\title{
DÜBLIN
}

Technological University Dublin

ARROW@TU Dublin

\section{Environmental impact assessment of Pinaceae airborne pollen and green infrastructure using BIM}

\author{
Santiago Fernández-Rodríguez \\ Universidad de Extremadura \\ Juan Pedro Cortés-Pérez \\ Universidad de Extremadura \\ Paloma Prieto Muriel \\ Universidad de Extremadura
}

See next page for additional authors

Follow this and additional works at: https://arrow.tudublin.ie/scschcpsart

Part of the Chemistry Commons, and the Environmental Sciences Commons

\section{Recommended Citation \\ Santiago Fernández-Rodríguez, Juan Pedro Cortés-Pérez, Paloma Prieto Muriel, Rafael Tormo-Molina, José María Maya-Manzano, Environmental impact assessment of Pinaceae airborne pollen and green infrastructure using BIM, Automation in Construction, Volume 96, 2018, Pages 494-507, ISSN 0926-5805, DOI: 10.1016/j.autcon.2018.10.011.}

This Article is brought to you for free and open access by the School of Chemical and Pharmaceutical Sciences at ARROW@TU Dublin. It has been accepted for inclusion in Articles by an authorized administrator of ARROW@TU Dublin. For more information, please contact arrow.admin@tudublin.ie, aisling.coyne@tudublin.ie, gerard.connolly@tudublin.ie.

Funder: Junta de Extremadura (Spain); European Regional Development Fund 


\section{Authors}

Santiago Fernández-Rodríguez, Juan Pedro Cortés-Pérez, Paloma Prieto Muriel, Rafael Tormo-Molina, and J. M. Maya-Manzano 


\title{
Environmental impact assessment of Pinaceae airborne pollen and green infrastructure using BIM
}

\author{
Santiago Fernández-Rodríguez ${ }^{\mathrm{a}, *}$, Juan Pedro Cortés-Pérez ${ }^{\mathrm{a}}$, Paloma Prieto Muriel $^{\mathrm{a}}$, \\ Rafael Tormo-Molina ${ }^{\mathrm{b}}$, José María Maya-Manzano ${ }^{\mathrm{c}}$ \\ a Department of Construction, School of Technology, University of Extremadura, Avda. de la Universidad s/n, Cáceres, Spain \\ ${ }^{\mathrm{b}}$ Department of Plant Biology, Ecology and Earth Sciences, Faculty of Science, University of Extremadura, Avda. Elvas $s / n$, Badajoz, Spain \\ ${ }^{c}$ School of Chemical and Pharmaceutical Sciences, Dublin Institute of Technology, Kevin Street, Dublin, Ireland
}

\section{A R T I C L E I N F O}

\section{Keywords:}

Building information modelling

Urban planning

Allergenic risk modelling

Pinaceae airborne pollen

Urban air quality assessment

\begin{abstract}
A B S T R A C T
Urban air quality is a parameter that plays a major role in human health at the local scale. Consequently, in urban planning, the behavior and potential risk of allergenicity for some pollen grains coming from ornamental trees and green spaces surrounding newly built buildings, should be considered. This paper aims to study how pollen exposure, influenced by weather parameters, can be assessed and integrated in the designing and building of constructions as other component of air quality assessment beforehand, by using BIM. Based on a comparative aerobiological study at the height over a building (sampled by two traps at ground and at $16 \mathrm{~m}$ ), a 3D local dynamic parametric scenario was modelled using BIM, and hourly average Pinaceae pollen concentrations (due to the closeness of pine trees to the samplers). From continuous recording (2009-2011) influenced by height and the influence of wind direction and speed was analysed. Additionally, a map of pine trees geolocated around the studied building was produced and the hourly average Pinaceae pollen concentrations were represented by Revit. BIM together with aerobiology can be a novel and useful tool for the construction of buildings considering airborne biological particles. This represents a first step towards the integration of some unusual environmental parameters in urban planning. Pollen grains modelling as an environmental health criterion for the construction of new buildings will allow technicians to avoid possible future isolation points in the design of building envelopes, and high pollen exposure rates could be avoided, creating 'allergy-free' buildings.
\end{abstract}

\section{Introduction}

Building information modelling (BIM)-based technologies and leanbased methods (construction and environmentally lean and efficient production) have been applied to environmental, social and economic concerns. This approach has contributed to the construction industry, playing a proactive role in the development of new sustainable services and manufacturing processes [1] and leveraging synergies between green aspects (environmental analysis, environmental science and sustainable development) and BIM and lean construction. Caiado et al. [2] indicated the need to consider social aspects coupled with the use of tools and techniques to advance sustainable development. Novel sustainability environmental indicators and pollution, such as life cycle $\mathrm{CO}_{2}$ emissions (LCCE) [3] or low-carbon building measure selection [4] in green buildings [5], have been assessed by BIM. Additionally, various indicators used to assess environmental impact, such as the greenhouse gas (GHG) footprint, eutrophication potential (EP), acidification potential (AP), human health $(\mathrm{HH})$ particulate, ozone depletion and smog, may be included [6,7]. BIM has evolved from 3D to computable $\mathrm{nD}$ through different industrial and urban code guidelines [8] that may be applied in urban planning and design [9]. BIM is a 3D digital data space for sharing building information that enables multi-disciplinary collaboration among various actors involved in the life cycle of buildings [10]. This technology allows the generation of a virtual prototype of the building to which a database is associated, as is proposed in this article with aerobiological data as part of air quality assessment. BIM models contain information beyond only geometry in terms of parametric data that can be manipulated in various analyses, quantity takeoffs, detailed documentation, etc. [10]. BIM software defines these objects parametrically so that if a related object is amended, dependent ones will also change automatically [11]. To generate the BIM models, Autodesk Revit is often used since it is one of the more well-known BIM authoring tools used for 3D modelling of complex development in the AEC industry [12].

\footnotetext{
* Corresponding author.

E-mail address: santiferro@unex.es (S. Fernández-Rodríguez).
} 


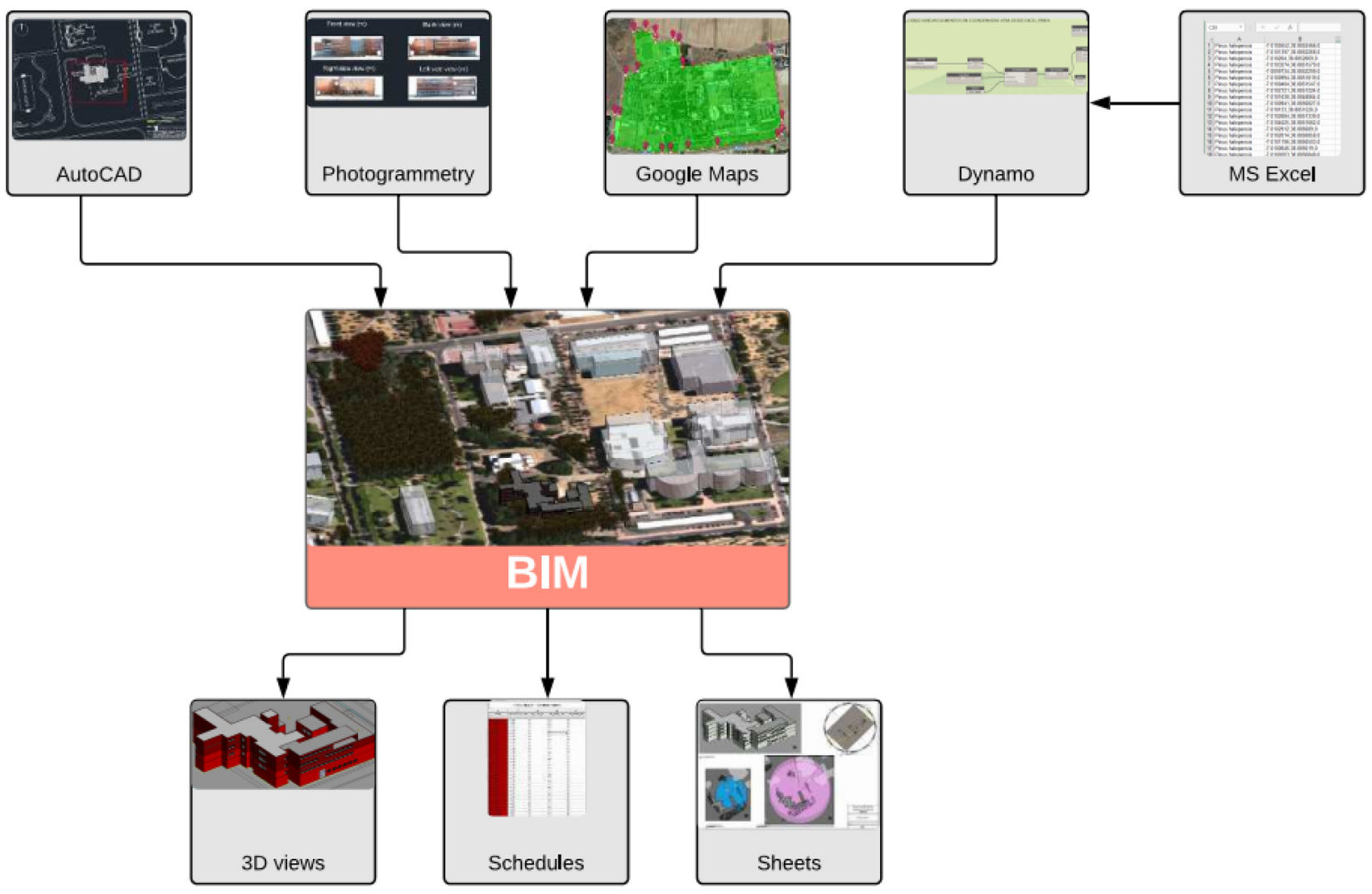

Fig. 1. BIM work scheme.

Integrating 4D in the evaluation of elevated urban projects is interesting for the simulation of phasing evaluation and decision makers [13]. So, the integration of 4D BIM models has been already applied to indoor air quality [14]. Urban planning has been studied from several points of view: empiric design evaluation [15], climate change in urban areas [16], environment and energy geographic information System (EGIS) [17], distribution of buildings in urban green space [18], urban sustainability management [19], infrastructure ecology as urban development [20] and green area management in urban ecological sustainability [21]. Consequently, the urban landscape is of great interest, and other studies have linked population and visual preferences for vegetated green space [22] and the effects of aesthetic quality [23]. A better understanding of the role of the urban environment [24] and ecosystem services is needed for making decisions [25] that impact socioeconomic factors [26] for assessing and evaluating sustainability comparisons of green infrastructure interventions [27]. Together with the benefits of urban green infrastructures relating to thermal aspects and land use [28,29], much attention has recently been paid to the origin of natural urban sources of pollution originating from ornamental trees, shrubs and herbs [30] due to human interactions in urban green spaces [31].

As a consequence of the construction process, habitat fragmentation occurs, which has effects on spatial patterning, particularly those creating obstacles to the dispersion of organisms and materials (nutrients, sediment or pollen) [32]. The importance of local scale in the assessment, monitoring and prediction of urban air quality has been highlighted [33] through the effect of urban canyons [34] or their influence on the heat island potential [34] and on thermal comfort afforded by trees [35]. Papers have studied the impacts of trees on particulate matter $\left(\mathrm{PM}_{2.5}\right)$ dispersion in urban streets [36,37] and microclimate and air quality in urban areas [38]. Another new parameter considered in urban impact assessment is aerobiology, which concerns the release of aerobiological particles, mainly pollen grains and fungal spores in the air, as well as bacteria, viruses or other bioaerosols. However, the most important aerobiological particles are pollen grains coming from trees such as Cupressaceae [39], Olea [40], Quercus [41] or from herbs as Poaceae [42,43].

Environmental impact assessment is linked with aerobiology through the changing climate [44]; modelling of environmental systems [42]; life cycle analysis and sustainability assessment [45]; characterization, management and treatment of atmospheric pollution [46]; and urban metabolism and ecological urbanism [47]. According to the main steps of environmental impact assessment protocols, the aerobiology fields are included as indicators (mainly pollen grains and fungal spores) of public works to be subsequently applied in the environmental inventory; preventive, corrective and compensatory measures; and environmental monitoring programmes $[48,49]$. Taking research and policy as tools to address the impacts of future risks provoked by pollutants should be considered as a mean to avoid exposure in future urban construction.

Based on a comparative aerobiological study over a building in a city in the SW Iberian Peninsula [50], Pinaceae pollen was one of the five main pollen types found, showing statistically significant differences in altitude, indicating that height influences the distribution of this pollen type. Moreover, the pine trees were close to the samplers, and the pollen had a limited capacity to float due to the large size of the grains $(>50 \mu \mathrm{m})$. Pinaceae pollen has been recorded at various distances; Pinus hallii is well represented locally, but its pollen is rarely recorded $>50 \mathrm{~m}$ from the parent trees. Long-distance transport of pollen occurs at a low frequency [51], and Pinus roxburghii pollen frequency declines rapidly as the distance from the source increases, with the highest densities $<100 \mathrm{~m}$ from the source [52]. In fact, FernándezRodríguez et al. [50] showed that Pinaceae was the only pollen type that showed a significant correlation between daily concentration at two heights with wind direction and speed. Direct exposure to the sun has been shown to be a significant parameter for both herbs and trees [53-56]. On the other hand, Pinaceae pollen has been considered in studies investigating ambient pollen concentrations and allergic 
problems [57-59] and has been shown to have a low prevalence of allergic sensitization [60]. All these features make this pollen type suitable to study over buildings with two samplers to analyse the influence of ornamental trees as local sources pollen grains. The use of new models of representation, such as BIM, is appropriate (Fig. 1).

The aim of this paper was to study how pollen exposure, taking into account weather parameters, can be assessed and integrated in the designing and building of constructions as other component of air quality assessment beforehand, by using BIM as tool. We propose BIM as a powerful tool to consider aerobiology as other component in air quality analysis, being this technic capable to model, simulate, analyse and visualize urban environments by combining parametric modelling with agent-based simulation.

\section{Materials and methods}

\subsection{Sampling site and pollen data}

The study was conducted in Badajoz, a city in the Extremadura region (SW Spain), from two sampling points at nearly the same place near the biology building $\left(38^{\circ} 88^{\prime} 28^{\prime \prime} \mathrm{N}, 7^{\circ} 00^{\prime} 85^{\prime \prime} \mathrm{W}\right)$ of the Faculty of Science, Badajoz Campus (University of Extremadura, Fig. 2), but at different heights (Fig. 3: one at ground level in the experimental garden (g) and the other at $16 \mathrm{~m}$ high in the terrace $(\mathrm{t})$, separated by a $20-\mathrm{m}$ horizontal distance. A 7-day volumetric sampler was used to record pollen [61]. According to previously published papers by Tormo-Molina et al. [62] and Maya-Manzano et al. [63], the adhesive petrolatum white (CAS number 8009-03-8) was used to capture airborne pollen. Standardized data procedures were followed as indicated by the Spanish Aerobiology Network (REA; [64]. The daily average $(0000-2400 \mathrm{~h})$ pollen counts and the intradiurnal variations-coordinated universal time (UTC) hourly counts were expressed as pollen grains $/ \mathrm{m}^{3}$ of air.

Pinaceae pollen was studied over 3 years (2009-2011), the main pollen season (MPS) being estimated using the 5-95\% range method [65]. According to this criterion, the pollen season starts on the date when the sum of pollen grains from the beginning of the year reaches or exceeds $5 \%$ of the total annual pollen concentration and ends when the
$95 \%$ of this total is reached or exceeded. To select episodes, the maximum hourly peaks were analysed. For the analysis of the intradiurnal pollen pattern, five continuous days $(120 \mathrm{~h})$ were selected that included the day with the peak pollen level in each year. These five days were selected depending on the pollen type at the ground (50.6\%) and terrace $(52.1 \%)$ levels.

\subsection{Meteorological data}

Various meteorological parameters were provided by the AT Delta-T DL2 fixed weather station situated at the experimental garden of the biology building on the Faculty of Sciences campus. This station is located 3 and $20 \mathrm{~m}$ from the garden and terrace samplers, respectively. The meteorological parameters considered in this study were wind direction (Wd), wind speed (Ws), sun hours (Sh), relative humidity (Rh), rainfall (R), solar radiation (Sr) and mean air temperature (Tmean).

\subsection{BIM technology applied to the management of pollen on buildings}

The use of BIM technology allowed the centralization of different types of information from different sources, such as geographic coordinates of trees, data in 2D CAD planes and data about pollen concentration, in a single 3D model to study and represent the pollen concentration in the envelope of the study building. First, the topography of the area was obtained through the Revit plugin that links data with Google Earth, called CADtoEarth. Then, modelling of the building and of its location in the environment was carried out. With the aim of creating a virtual prototype of the building, we started with the information contained in the 2D CAD plans, with the on-site representation of the buildings that make up the Badajoz campus provided by the University of Extremadura. From these plans, we obtained the dimensions, orientation and relative positioning of the buildings (Fig. 2). To obtain information on the elevation, dimensions, and location of the windows and doors, photogrammetry was used to obtain 2D elevations (Fig. 3). From this information, modelling of the building was carried out at its real location (Fig. 4). The model building consisted of the exterior volume, including the windows and doors of the facades. Each of the facades was modelled in sections that correspond to

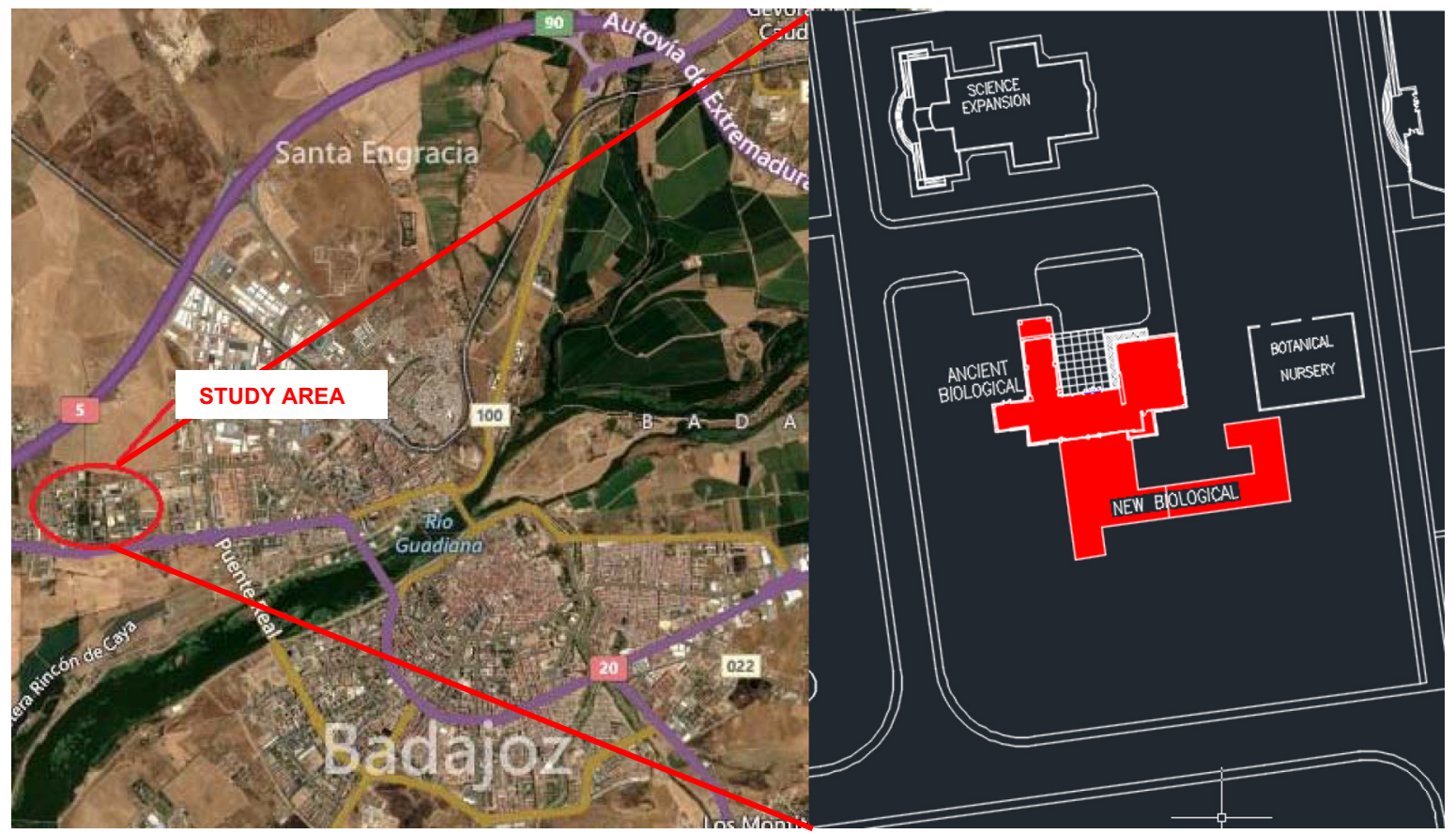

Fig. 2. Defined area of the Badajoz Campus belonging to the University of Extremadura. 


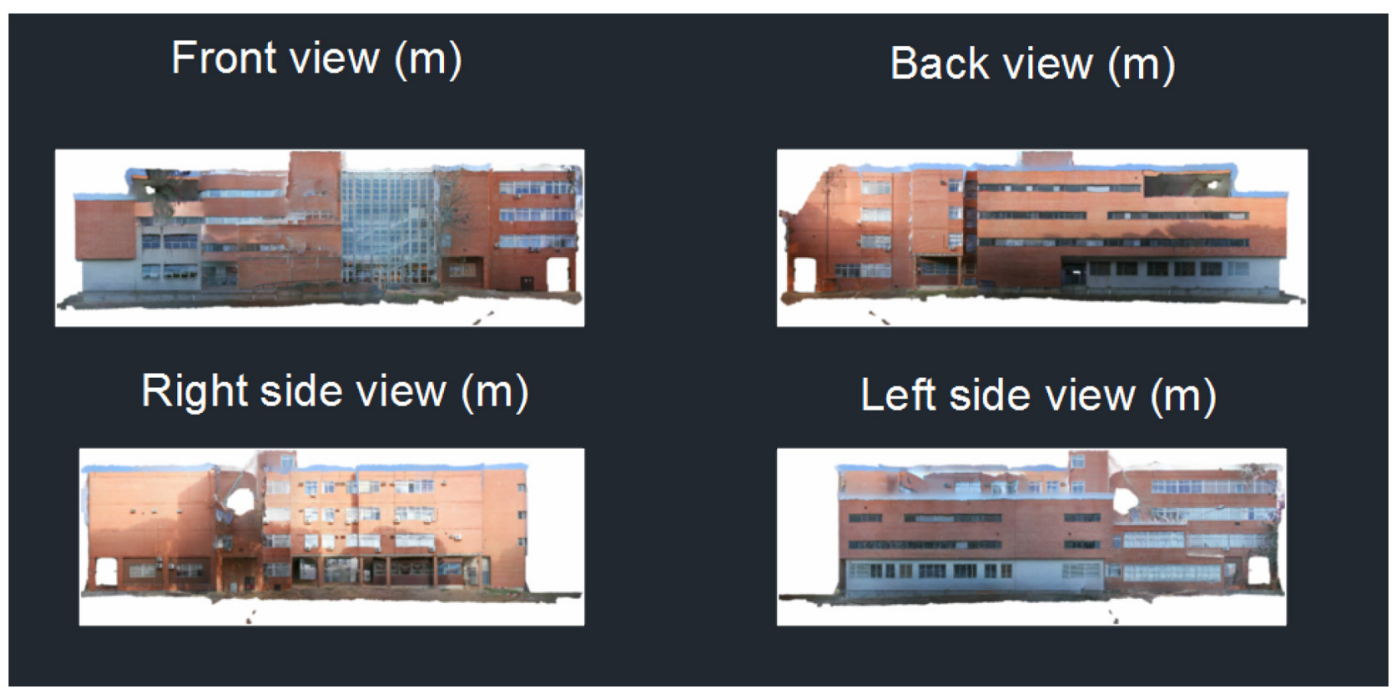

Fig. 3. 2D elevations of the building. Photogrammetry.

the heights of the floors of the building. To show the influence of height on pollen concentration, a pollen concentration parameter was created in the facade elements, these being the elements most exposed to pollen. Once the building in Revit had been modelled and located, each tree was placed in its exact position. The placement in the model of the 557 Pinus spp. included in the study was done using their UTM coordinates. For this, the Revit plugin (DYNAMO) was used (Fig. 5). The Autodesk Revit API (Application Programming Interface) enables users to add features to the software [66] and automate tasks through visual programming codes. Dynamo is a visual programming environment that extends the parametric modelling capabilities of Revit by adding a level of associativity that does not exist in the standard application [66]. The arrangement of these features is fundamental for the analysis of the effect of pollen on the study building, considering variables such as wind direction, temperature with respect to height and possible interference with the environment. This approach made it possible to introduce unrelated information coming from different sources in a single model, in turn allowing us to integrate and interrelate elements of interest, which were the building and the trees in their corresponding locations, in the study (Fig. 6).

According to Fernández-Rodríguez et al. [50], there is a significant influence of the height of the samplers on the daily concentration of pollen grains. Revit allows the user to define parameters and their 3D representation. To analyse the spatial variation in pollen, a parameter called "Pinaceae pollen concentration" was generated in the Revit model. To analyse this spatial variation in relation to the rest of the factors that influence the concentration, a 3D representation of the model and the environment was obtained, forming a single file with an associated database. In this study, the walls that make up the envelope defined a series of parameters that allowed the introduction of values corresponding to the pollen concentrations at variable heights. These pollen concentrations were obtained from a linear interpolation between the pollen concentration values from the samplers located in the terrace and in the garden. After data entry, visualization filters were generated to represent the concentration of pollen in each of the sections of the building based on the study variables. To do this, chromatic scales were defined that indicate the variation in the pollen concentration by height. 3D figures of the complete model were obtained, including the representation of the nearest Pinus spp. [51,52], which produced radii of action at 50, 100 and $150 \mathrm{~m}$ that directly affected the Pinaceae pollen that reached the building envelope.

\section{Results}

\subsection{Urban map of pines trees}

A total of 557 pine trees were counted, namely, 445 Pinus pinea and 112 Pinus halepensis, in a total of $0.53 \mathrm{~km}^{2}$, which corresponds to the entire area of the campus. Considering each of the samplers (garden and terrace) as a centre, action radii were established at distances of 50, 100 and $150 \mathrm{~m}$ to obtain the number of trees regardless of their species that were contained and therefore able to influence the pollen concentration at the samplers. Fig. $7 \mathrm{a}-\mathrm{c}$ shows the geolocation of pine trees around each sampler and each radius of action near the biology building of the

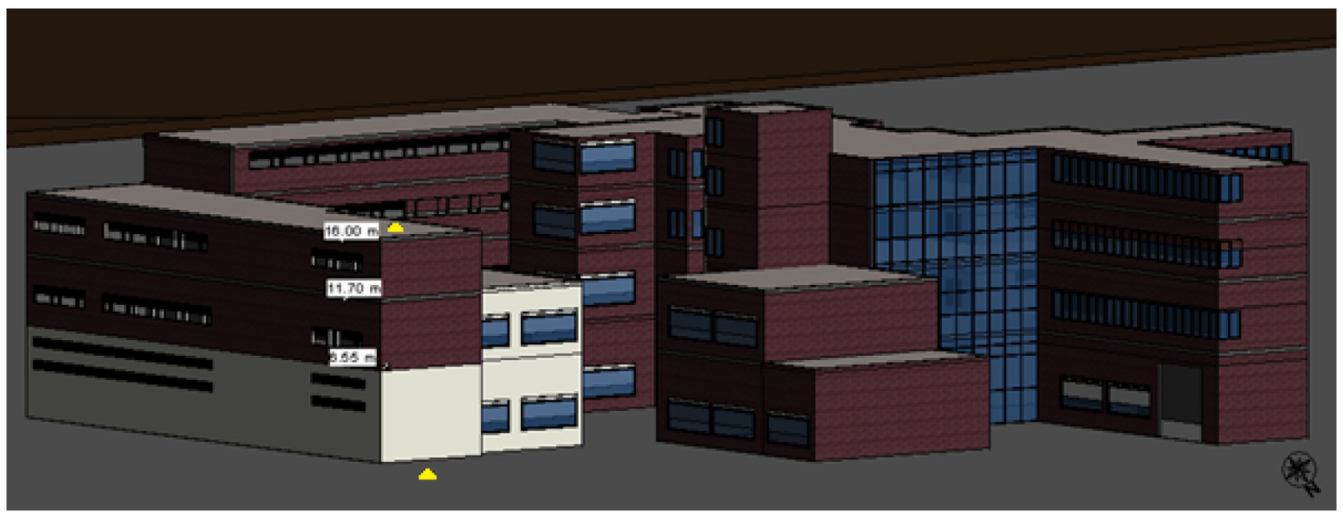

Fig. 4. BIM model of the building. 


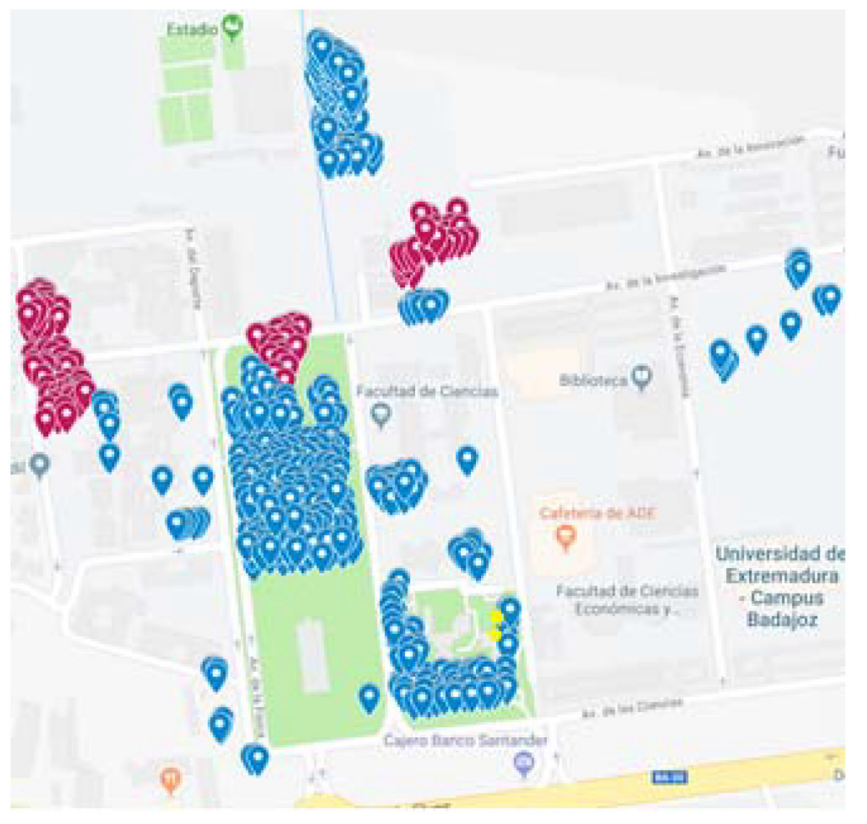

\begin{tabular}{|c|c|c|}
\hline \multicolumn{2}{|c|}{ C38 } & $\checkmark \quad f_{x}$ \\
\hline$\Delta$ & A & $\mathrm{B}$ \\
\hline 1 & Pinus halepensis & $-7.0100552,38.8852466,0$ \\
\hline 2 & Pinus halepensis & $-7.0101397,38.8852268,0$ \\
\hline 3 & Pinus halepensis & $-7.010204,38.8852069,0$ \\
\hline 4 & Pinus halepensis & $-7.0103274,38.8851579,0$ \\
\hline 5 & Pinus halepensis & $-7.0099734,38.8852299,0$ \\
\hline 6 & Pinus halepensis & $-7.0100994,38.8851819,0$ \\
\hline 7 & Pinus halepensis & $-7.0100404,38.8851547,0$ \\
\hline 8 & Pinus halepensis & $-7.0102121,38.8851224,0$ \\
\hline 9 & Pinus halepensis & $-7.0101638,38.8848864,0$ \\
\hline 10 & Pinus halepensis & $-7.0100941,38.8850827,0$ \\
\hline 11 & Pinus halepensis & $-7.010133,38.8851526,0$ \\
\hline 12 & Pinus halepensis & $-7.0102684,38.8851339,0$ \\
\hline 13 & Pinus halepensis & $-7.0104025,38.8851662,0$ \\
\hline 14 & Pinus halepensis & $-7.0102912,38.885089,0$ \\
\hline 15 & Pinus halepensis & $-7.0102014,38.8850858,0$ \\
\hline 16 & Pinus halepensis & $-7.0101196,38.8850503,0$ \\
\hline 17 & Pinus halepensis & $-7.0100646,38.885019,0$ \\
\hline 18 & Pinus halepensis & $-7.0100203,38.8850848,0$ \\
\hline
\end{tabular}

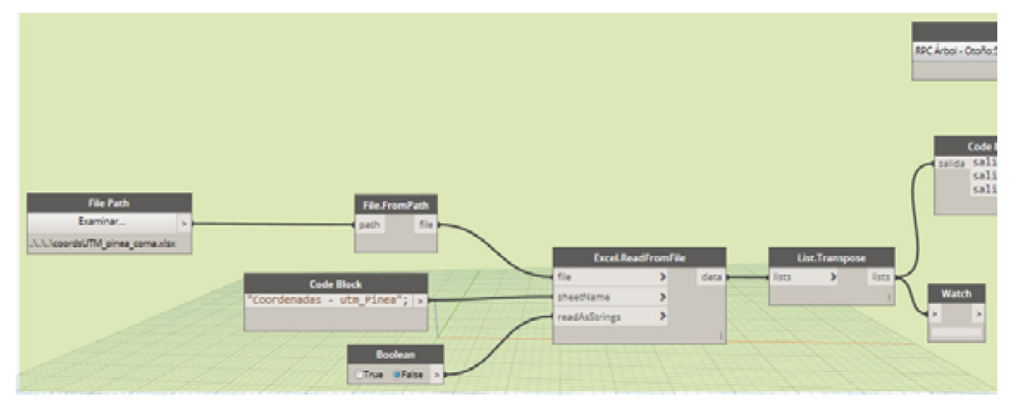

Fig. 5. Dynamo code to locate elements by coordinates.

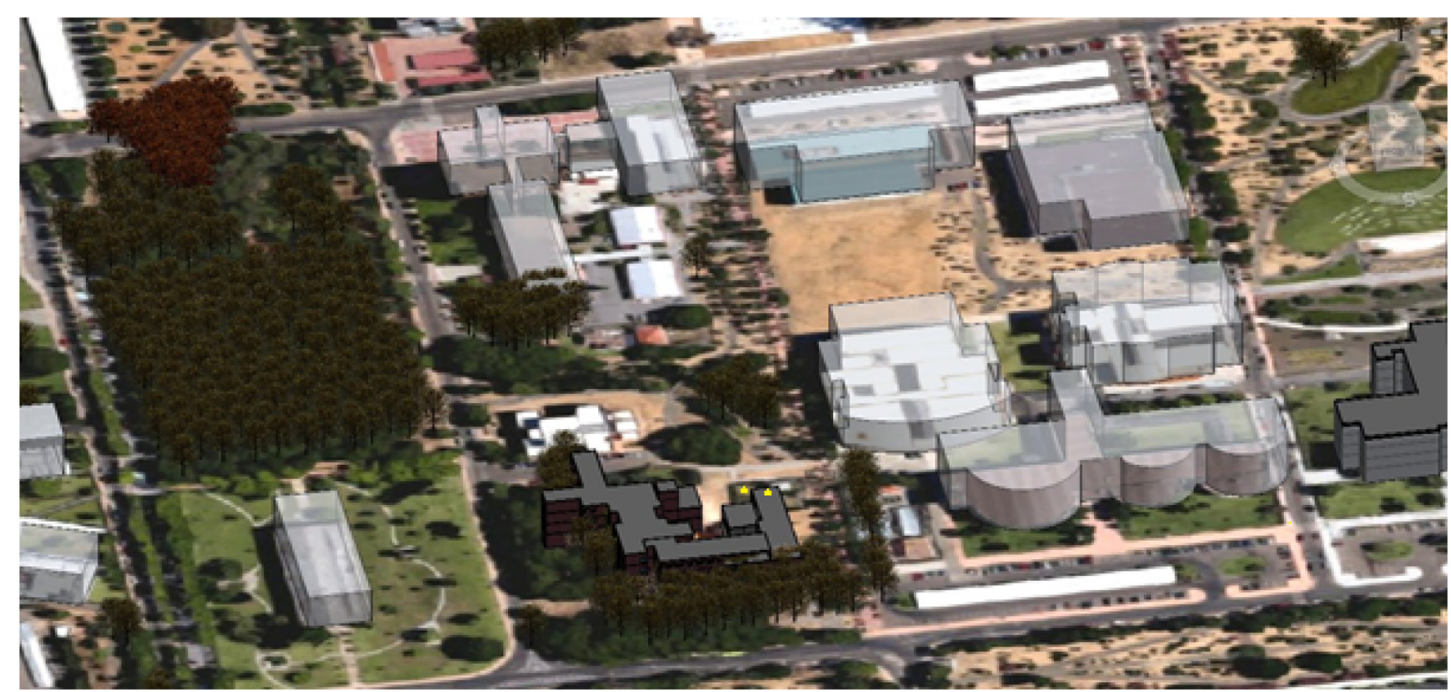

Fig. 6. Location of pollen traps including Pinus spp. and the meteorological station.

Badajoz Campus of the University of Extremadura.

\subsection{Hourly analysis of episodes}

Based on a previous study by Fernández-Rodríguez et al. [50], the hourly average Pinaceae concentration from 2009 to 2011 at 0800,
1400 and $2000 \mathrm{~h}$ using Revit (Fig. 8) was recorded. The selected episodes for the maximum daily Pinaceae pollen included 3 annual periods with a total of 15 days; 22nd-26th April 2009, 28th April-2nd May 2010 and 16-20th April 2011 (Fig. 8). Table 1 shows the hourly concentration and meteorological comparison by height. We found a highly statistically significant positive correlation for Pinaceae concentration 
(a)

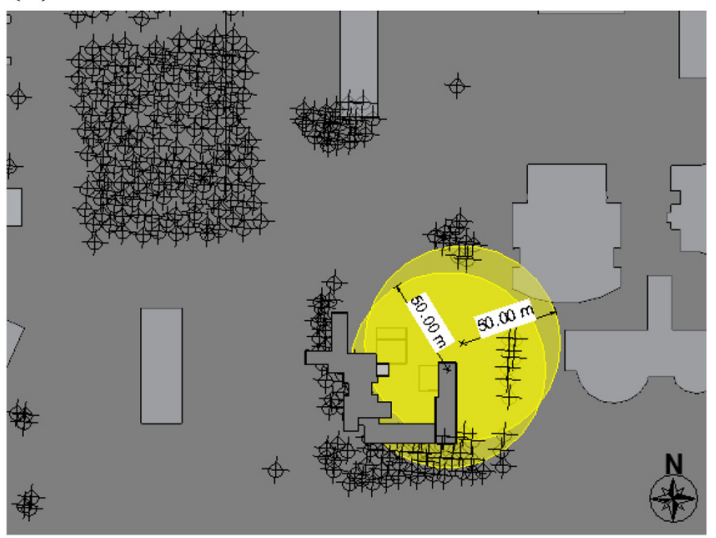

(b)

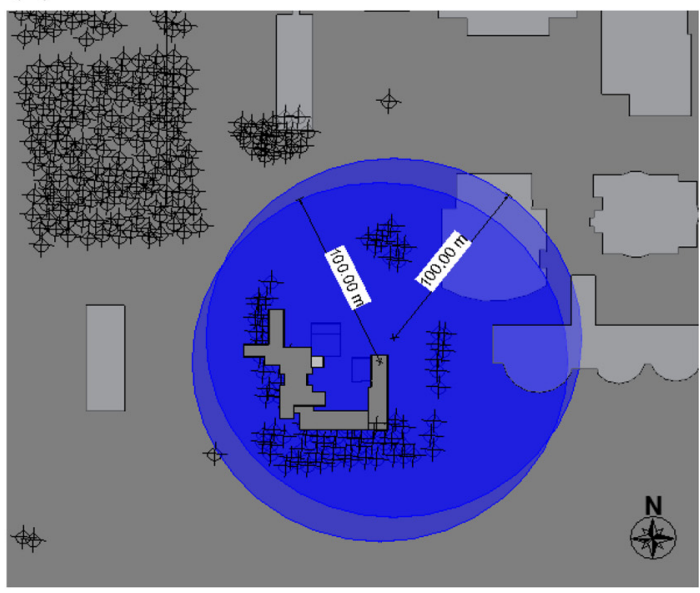

(c)

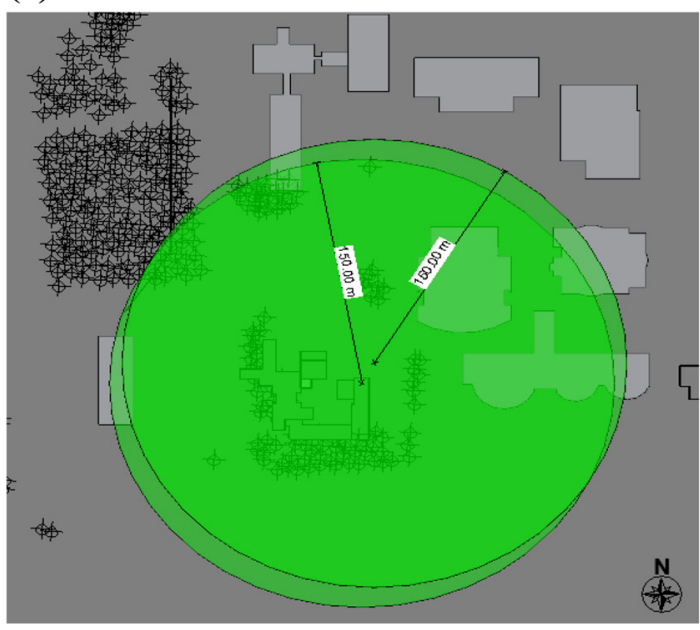

Fig. 7. Pines trees geolocated at the campus of the University of Extremadura in Badajoz at $50 \mathrm{~m}$ (a), $100 \mathrm{~m}$ (b) and $150 \mathrm{~m}$ (c) from the samplers at ground and terrace levels at the biology building.

in all episodes. However, the maximum peaks did not occur on the same day in all cases. Hourly peaks occurred, on average, between 13 and $16 \mathrm{~h}$ in most cases, although peaks could appear at nearly any hour of the day, including night hours. Peaks occurred on average first at $16 \mathrm{~m}$ on the terrace and $2.5 \mathrm{~h}$ later at ground level. Two similar hourly peaks on the same day appeared in some cases but on only 2 out of the 15 days studied. Likewise, an advance of $0.69 \mathrm{~h}(41.4 \mathrm{~min})$ for the terrace and $0.76 \mathrm{~h}(45.6 \mathrm{~min})$ for the ground was found when the maximum concentrations were compared with the highest wind speed during this interval. It could be due to that for pollen releasing, to reach the gust of wind is not needed, and previous rises on wind speed are enough to allow this release. Hourly mean temperature and solar radiation showed a statistically significant positive correlation with hourly peaks, and relative humidity showed a negative correlation. Speed and wind direction showed different significant correlations depending on the episode. Fig. 9 represents the intradiurnal Pinaceae pollen levels, together with the main directions which increased Pinaceae concentrations and frequency for wind speed and direction. The main wind direction in the 2010 and 2011 episodes was between $125^{\circ}$ and $175^{\circ}$, whereas it was between $150^{\circ}$ and $200^{\circ}$ on the study days in 2009 . The maximum values of wind speed were the same in the 2010 episode. Fig. 10 shows a 3D representation of the urban map with pines trees around the biology building and the speed and direction wind for selected three hourly cases on 29 April 2010. In this particular case, the Pinaceae concentration changed in $3 \mathrm{~h}(12-14 \mathrm{~h})$ : from 3140 grains $/ \mathrm{m}^{3}$ $(12 \mathrm{~h})$ with a wind speed of $0.36 \mathrm{~m} / \mathrm{s}$ and the wind direction blowing from $122^{\circ}$ (SE), to 3866 grains $/ \mathrm{m}^{3}(13 \mathrm{~h})$ with $0.61 \mathrm{~m} / \mathrm{s}$ and $106^{\circ}$ (E$\mathrm{SE}$ ), and finally 1868 grains $/ \mathrm{m}^{3}$ at $14 \mathrm{~h}$ with a wind speed of $1.19 \mathrm{~m} / \mathrm{s}$ and a wind direction of $213^{\circ}$ (SW).

\section{Discussion}

Despite the fact that there is now international awareness of the regulation of urban green spaces, studies on the design of green areas [67] do not include aerobiological information or the interaction of tree species in these spaces with the surrounding buildings $[18,68]$. Our results may serve to advance the incorporation of aerobiological information as an element of the design of green infrastructures, potentially avoiding the entrance of pollen on them. In this case, pines trees in BIM models of green areas and modelling of buildings in their environment. The methodology followed in this study is based on the scheme proposed by Aschwanden et al. [15]. This work developed a 3D model based on contour lines as masses in Zurich (Switzerland). This model considered geographical parameters (topography, elevation, obstacles, land use and skyline) to investigate topics such as accessibility of amenities, quality of services and pedestrian comfort. In the same way, in the present study, we modelled part of Badajoz Campus (Spain) using information from environmental topography maps, the species to be investigated and their geolocation, the contour of the buildings as masses and various circulation zones. However, more urban aspects linked to air quality components and infrastructures could be considered using the results shown in our maps, including the proximity of ornamental fountains to citizens, healthy itineraries and building access areas, including the main windows exposed to allergenic risk. The study focused on the interaction of pollen with walks and buildings, analysing the 3D diffusion through the representation of the concentration of pollen on the envelope of the building closest to the samplers. This building was also modelled in greater detail using photogrammetry performed on its entire perimeter, which allowed us to precisely define the external volume and envelope, including the windows and doors [69], which are important for the quality of the indoor environment of the building [70]. According to green areas management practices, planting trees to improve local air quality has been considered [21]. This paper indicated that a major challenge to this is finding the best solution for a peculiar natural context in which an intervention is required.

To analyse the variation in pollen concentration, we used a previously described methodology [14], where the outdoor dust concentration was analysed using BIM and the effects inside the building were considered together with the number of sources in the same way that in our study. In our study, pollen dispersion was considered according to the number of producing elements (trees) through the creation of circles of different radii that included an increasing number of pollen-generating trees with increasing area. A previous study 


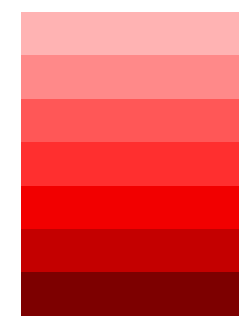

HOUR

0800

1400

2000
Pinaceae pollen concentration 60-100 grains $/ \mathrm{m}^{3}$ Pinaceae pollen concentration 101-140 grains $/ \mathrm{m}^{3}$ Pinaceae pollen concentration 141-180 grains $/ \mathrm{m}^{3}$ Pinaceae pollen concentration 181-220 grains $/ \mathrm{m}^{3}$ Pinaceae pollen concentration 221-260 grains $/ \mathrm{m}^{3}$ Pinaceae pollen concentration 261-300 grains $/ \mathrm{m}^{3}$ Pinaceae pollen concentration 301-340 grains $/ \mathrm{m}^{3}$

\section{REVIT}

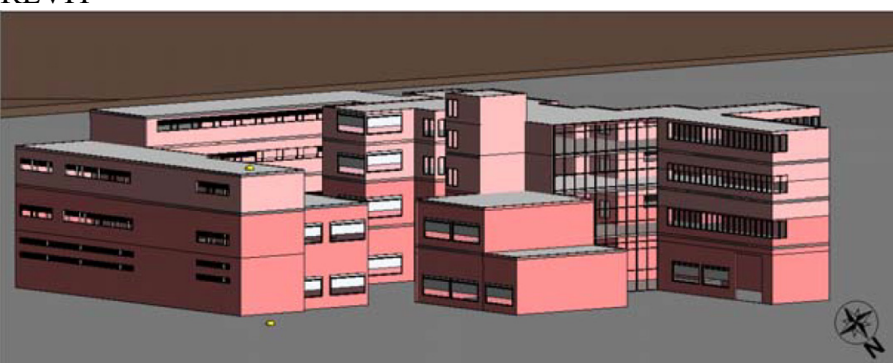

Fig. 8. Hourly (0800, 1400 and 2000 h) average Pinaceae concentrations from 2009 to 2011.

Table 1

Spearman's correlation test comparing the hourly Pinaceae pollen concentration in the terrace level at $16 \mathrm{~m}(\mathrm{t})$ and at ground level $(\mathrm{g})$ during the selected test periods (22-26 April 2009, 28 April to 2 May 2010 and 16-20 April 2011).

\begin{tabular}{|c|c|c|c|c|c|c|c|c|c|}
\hline 2009 & Statist & $\mathrm{t}$ & $g$ & Rain & Tmed & Ws & Wd & RH & Rad \\
\hline \multirow[t]{2}{*}{$\mathrm{t}$} & $\mathrm{r}$ & & $0,729^{* * *}$ & . & $0,323^{* *}$ & $0,383^{* *}$ & 0,101 & $-0,325^{* * *}$ & $0,443^{\text {*** }}$ \\
\hline & $\mathrm{p}$ & & 0,000 & . & 0,000 & 0,000 & 0,274 & 0,000 & 0,000 \\
\hline \multirow[t]{2}{*}{$g$} & $\mathrm{r}$ & $0,729^{* *}$ & & . & $0,380^{* *}$ & $0,550^{* *}$ & 0,123 & $-0,383^{* * *}$ & 0,364 ** \\
\hline & $\mathrm{p}$ & 0,000 & & . & 0,000 & 0,000 & 0,181 & 0,000 & 0,000 \\
\hline 2010 & Statist & $\mathrm{t}$ & $g$ & Rain & Tmed & Ws & Wd & RH & Rad \\
\hline \multirow[t]{2}{*}{$\mathrm{t}$} & $\mathrm{r}$ & & $0,940^{* *}$ & . & $0,261^{\text {*** }}$ & $0,612^{* *}$ & 0,089 & $-0,364^{* * *}$ & $0,518^{* * *}$ \\
\hline & $\mathrm{p}$ & & 0,000 & . & 0,004 & 0,000 & 0,335 & 0,000 & 0,000 \\
\hline \multirow[t]{2}{*}{$g$} & $\mathrm{r}$ & $0,940^{* * *}$ & & . & $0,277^{* * *}$ & $0,674^{* *}$ & 0,152 & $-0,391^{* * *}$ & $0,508^{* *}$ \\
\hline & $\mathrm{p}$ & 0,000 & & . & 0,002 & 0,000 & 0,097 & 0,000 & 0,000 \\
\hline 2011 & Statist & $\mathrm{t}$ & $g$ & Rain & Tmed & Ws & Wd & $\mathrm{RH}$ & Rad \\
\hline \multirow[t]{2}{*}{$\mathrm{t}$} & $\mathrm{r}$ & & $0,842^{* * *}$ & $-0,049$ & $0,327^{* *}$ & 0,165 & $-0,103$ & $-0,265^{* *}$ & 0,154 \\
\hline & $\mathrm{p}$ & & 0,000 & 0,596 & 0,000 & 0,072 & 0,265 & 0,003 & 0,092 \\
\hline \multirow[t]{2}{*}{ g } & $\mathrm{r}$ & $0,842^{* *}$ & & $-0,054$ & $0,284^{* * *}$ & $0,209^{*}$ & $-0,233$ & $-0,206^{*}$ & 0,173 \\
\hline & $\mathrm{p}$ & 0,000 & & 0,560 & 0,002 & 0,022 & 0,010 & 0,024 & 0,058 \\
\hline
\end{tabular}

** Correlation; significant at 0.01 level (bilateral).

* Correlation; significant at 0.05 level (bilateral). 
(a)

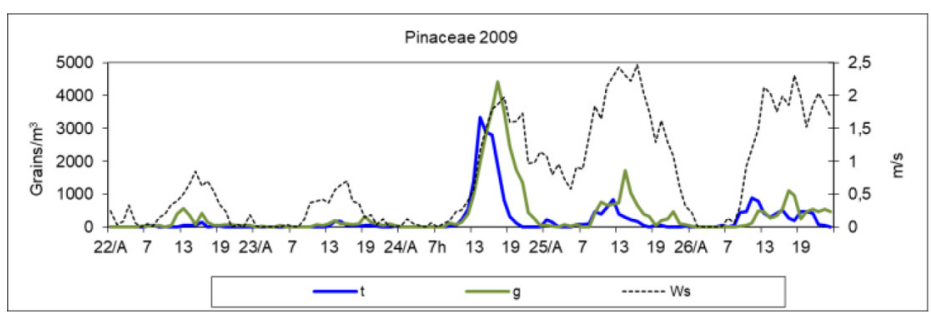

(c)

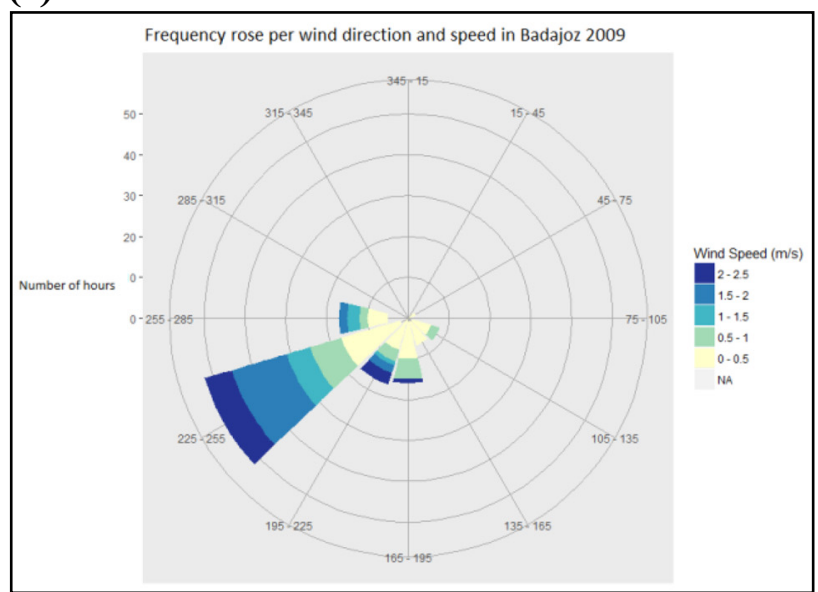

(d)

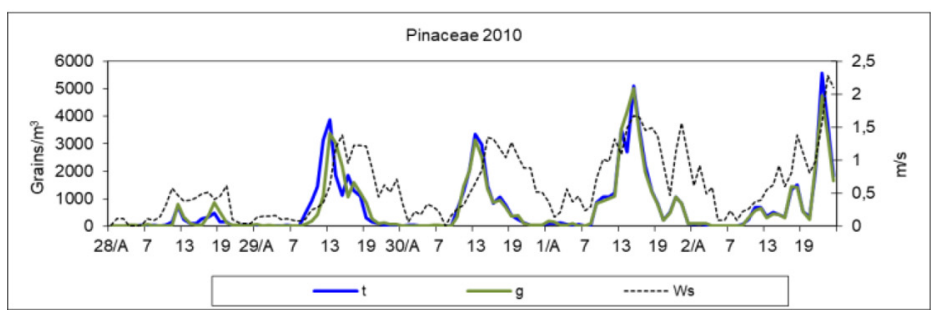

(f)

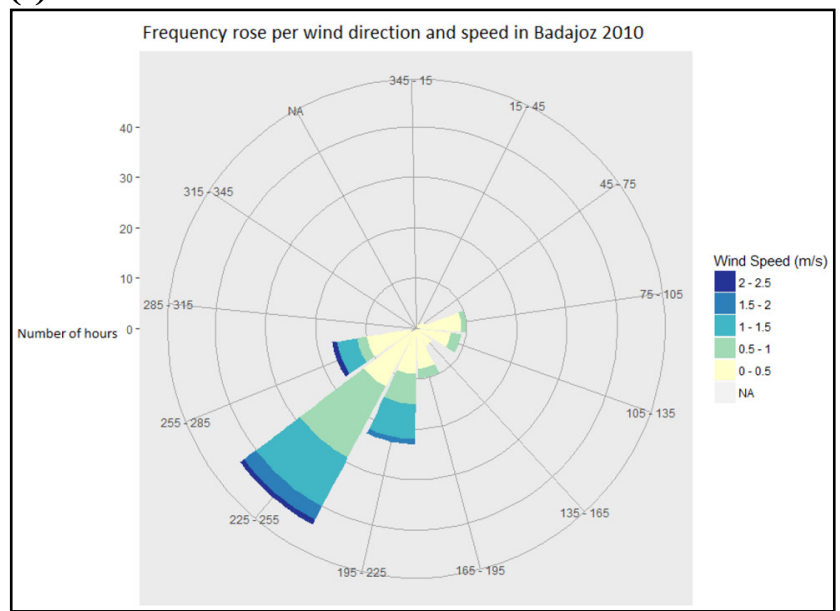

(b)

Hourly average pollen concentrations sums (pollen grains $\mathrm{m}^{-3}$ ) and $\mathrm{Wd} 2009$

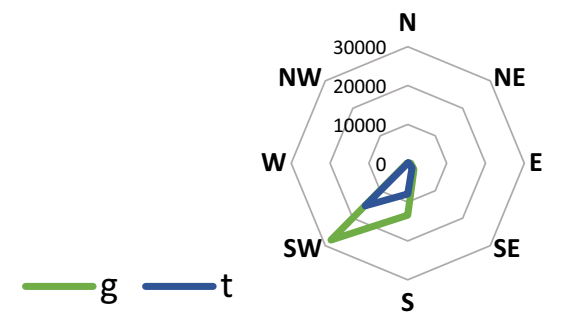

(e)

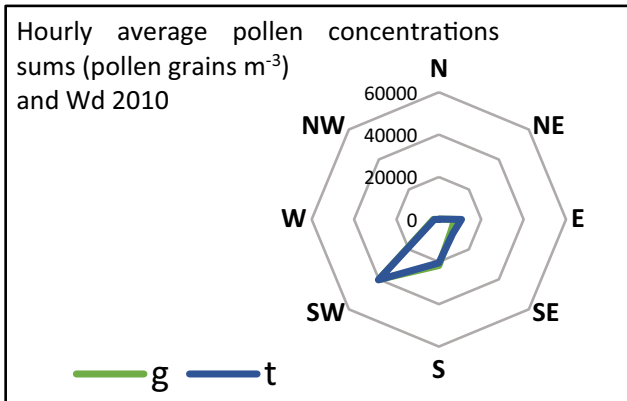

Fig. 9. Intradiurnal Pinaceae pollen concentrations at $16 \mathrm{~m}(\mathrm{t})$ and at ground level $(\mathrm{g})$ with wind speed (Ws) and direction (Wd). 
(g)

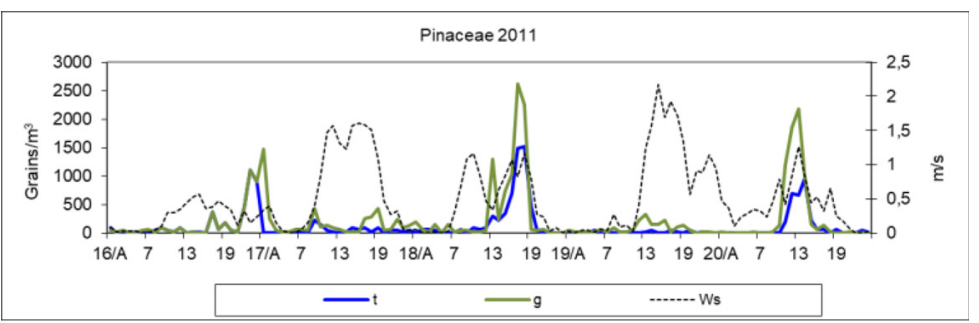

(h)

Hourly average pollen concentrations sums (pollen grains $\mathrm{m}^{-3}$ ) and $\mathrm{Wd} 2011$

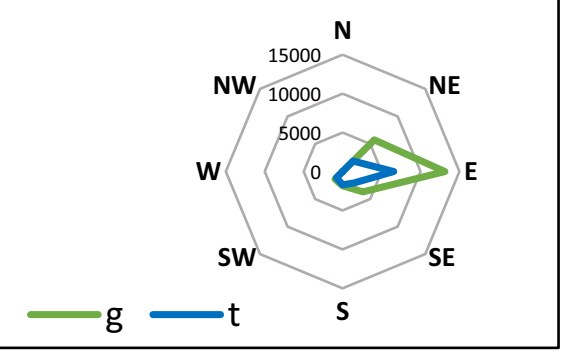

(i)

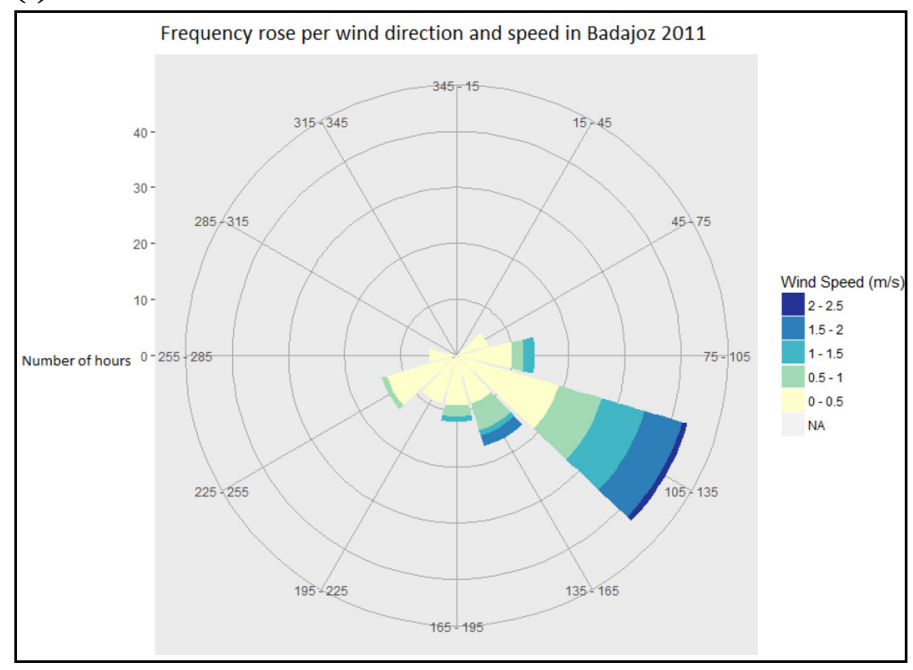

Fig. 9. (continued)

calculated the pollen production from other Mediterranean pines species (Pinus pinaster) per meter of tree crown, that could be comparable with the species here considered, obtaining values ranged $3-5 \cdot 10^{9}$ pollen grains per meter of tree crown diameter [71]. Altaf et al. [14] introduced ventilation as an important factor within the BIM model. In this study, wind direction, which was demonstrated to be correlated with pollen concentration, was included in the model. The wind direction pattern within a city is an important parameter to be consider because it affects measurement of the pollen concentration coming from those sources located in the path of the main wind direction to the pollen trap and can lead to overestimation [63,72]. Consequently, modelling carried out using BIM has shown to be a powerful tool to interpret these spatial variations at a very local scale of a few dozen of metres. This knowledge provides an opportunity to understand the pollen gradient because thus far, there has been a gap in aerobiology concerning this scale, and only a few articles have analysed height pollen gradients [73].

The 3D visualization of the hourly average concentration Pinaceae pollen is shown in Fig. 8. This result can be included within smart green city development, specifically in terms of health. Similar results have been obtained by the Korean government [74], where an application was developed to visualize temperature, humidity and $\mathrm{CO}_{2}$ in $3 \mathrm{D}$. Data about the proximity of ornamental sources to building doors can help to determine areas with a higher risk of high pollen levels, providing a new parameter for environmental and allergological assessment. Analysing these data could help to manage building access through green spaces, assuming advances from other accessibility studies [75]. In this previous study, the authors established an automatic building accessibility diagnosis from point clouds in four real case studies in Vigo using a methodology with straight streets of approximately $150 \mathrm{~m}$, with trees on sidewalks and building entrances to shops and dwellings. An effect of altitude over the facades of buildings was observed. Our study showed similar results with other parameters, including hourly average Pinaceae concentration (Fig. 9) and hourly wind direction and speed (Fig. 10). Balado et al. [75] only addressed the point of view of physical disabilities, whereas our proposal identifies areas with higher concentrations of pollen, which is fundamental information for the management of accessibility to spaces for people with allergies.

Currently, there are various proposals for BIM dimensions that extend from $3 \mathrm{D}$ to $6 \mathrm{D}$ or $7 \mathrm{D}[8,76]$. In these studies, BIM dimension proposals are associated with aspects intrinsic to the building and its construction, such as execution time, cost and maintenance. The results presented in this study allow us to approach a new dimension for the BIM in which the building is placed in context with its environment, in this case, airborne pollen. This approach opens a new dimension in BIM modelling, allowing the introduction of allergenic species that are important for aerobiological purposes as new criteria in the design of buildings using BIM methodology. From this perspective, green building research focusing on ventilation is an interesting field of study [77].

As in a previous study of ornamental pollen types from cities in the SW Iberian Peninsula, Pinaceae pollen was important based on the concentration and number of ornamental trees [47]. In that study of cities in Extremadura with a smaller population and a lower density of pine trees per hectare, 577 Pinaceae trees in Don Benito, 295 pine trees in Plasencia and 207 in Zafra were counted. Its abundance is justified 


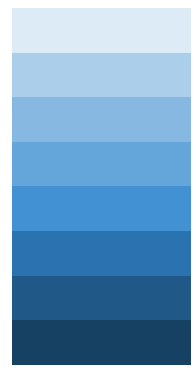

Pinaceae pollen concentration 1000-1400 grains $/ \mathrm{m}^{3}$ Pinaceae pollen concentration 1400-1800 grains $/ \mathrm{m}^{3}$ Pinaceae pollen concentration 1800-2200 grains $/ \mathrm{m}^{3}$ Pinaceae pollen concentration 2200-2600 grains $/ \mathrm{m}^{3}$ Pinaceae pollen concentration 2600-3000 grains $/ \mathrm{m}^{3}$ Pinaceae pollen concentration 3000-3400 grains $/ \mathrm{m}^{3}$ Pinaceae pollen concentration 3400-3800 grains $/ \mathrm{m}^{3}$ Pinaceae pollen concentration 3800-4200 grains $/ \mathrm{m}^{3}$

\section{REVIT}

(10a) HOUR: 1200 WIND SPEED: $0.36 \mathrm{~m} / \mathrm{s} \quad$ WIND DIRECTION: $122.8^{\circ}$
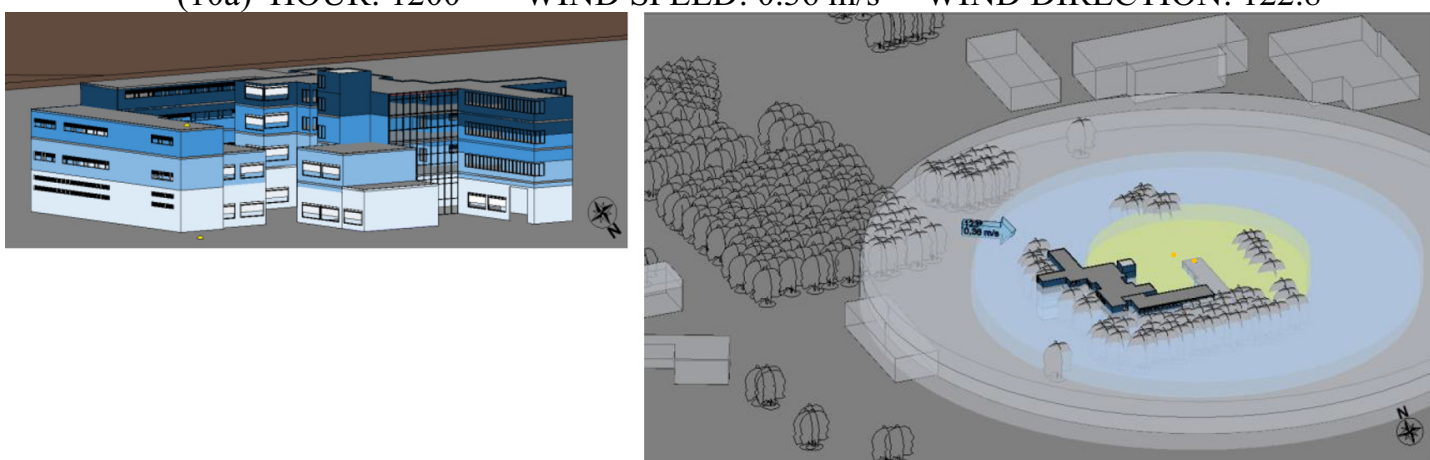

(10b) HOUR: 1300

WIND SPEED: $0.61 \mathrm{~m} / \mathrm{s}$
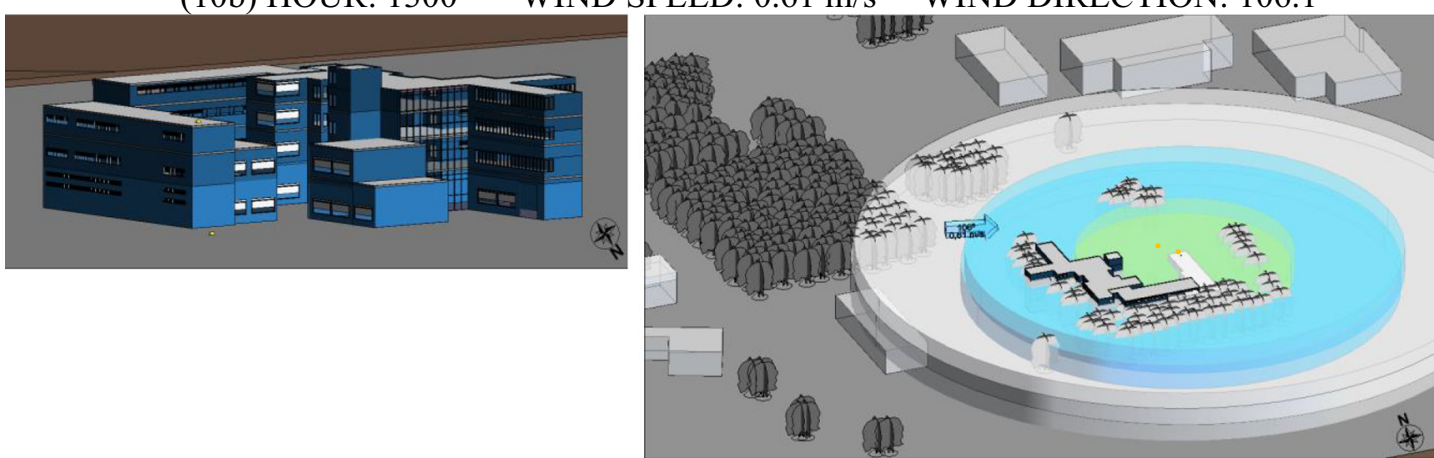

(10c) HOUR: $1400 \quad$ WIND SPEED: $1.19 \mathrm{~m} / \mathrm{s}$
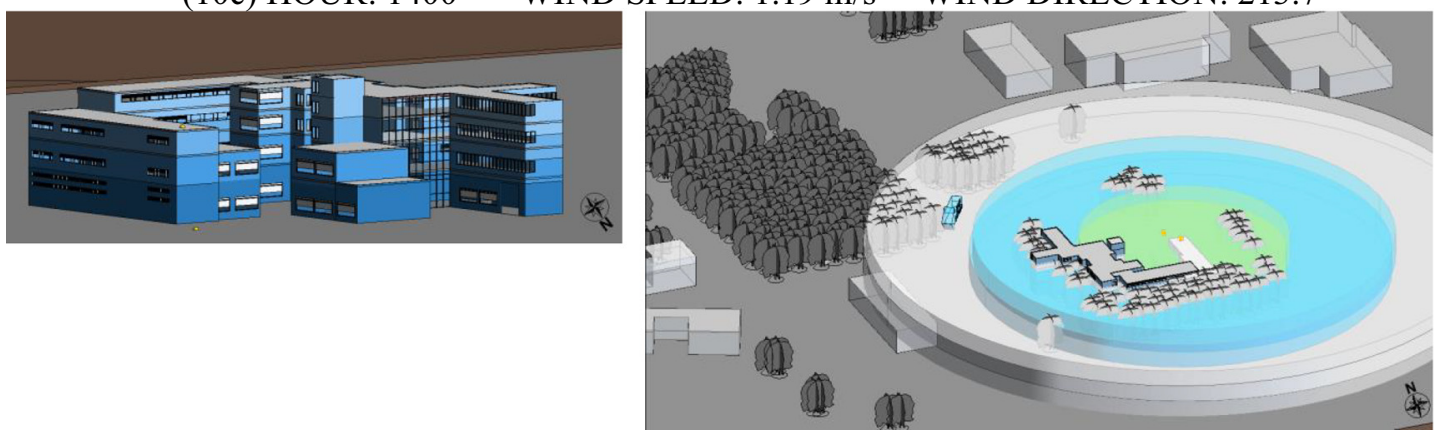

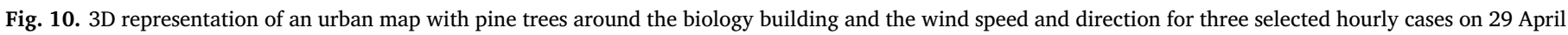
2010.

due to the role played by Pine trees, which provide ecosystem services in urban plans, including urban temperature regulation, air purification and recreation [25]. Pine trees can be considered for use in garden cities and eco-urbanism [78]. The size of the urban area we studied was similar to that of previous studies $[33,79,80]$. Our study can serve to highlight the importance of considering ornamental flora at the local scale for assessing, monitoring and predicting air quality in urban areas [33,81].

The intradiurnal variation in Pinaceae pollen during the selected episodes showed a similar hourly pattern with two peaks, one maximum at midday and another at the end of the evening. Similar results were found in previous studies of the annual main pollen season of Pinacae pollen in Mediterranean countries such as Portugal [82], Spain [50] and Turkey [83]. Peaks occurred on average first at the terrace and $2.5 \mathrm{~h}$ later at ground level. On the same day, 2 similar hourly peaks appeared in some cases (15 days). Kong et al. [35] investigated the effect of wind flow on a street canyon with trees. The flow of air passes the building and passes through the crown of the tree by convention. In this process, the air can be associated with pollen particles from the tree. The coincidence of these results with hourly data, including the maximum concentrations, highlights the importance of using hourly data in considering new urban environmental planning scenarios. 
The relationship of Pinaceae pollen concentration and hourly meteorological data showed a positive statistically significant correlation with mean temperature and a negative statistically significant correlation with relative humidity. However, there was no rainfall during the 2009 and 2010 testing periods, but rain did occur in 2011, when a negative correlation was found. These results are in line with those of previous studies $[82,83]$. In our study, a positive effect of wind speed for all episodes is consistent with the results of Ribeiro et al. [82] but disagrees with the results obtained by Uguz et al. [83]. This fact might be related to the distance $(0.6 \mathrm{~km})$ from the meteorological station to the pollen trap, in contrast with our case, where both stations were closer. Furthermore, a map of ornamental trees was not supplied, so the analysis of the proximity of the ornamental sources and the wind speed could not be performed. Damialis et al. [84] indicated that the absence of a relationship between wind components and pollen counts for $\mathrm{Cu}$ pressaceae might be explained by the fact that this plant taxon has a high local distribution. Although sources were more abundant in the SW and W, from where the wind predominantly blew, the wind direction did not show a statistically significant correlation with Pinaceae pollen. It can be due to the nearness of the sources to the pollen traps, with the possibility that refloating processes increasing the concentrations outside the main pollen season, especially with gardening work that was being done during the day in the campus. Also the presence of buildings with different materials (which suffer different levels of insolation, saving heat in a different way) and heights (offering shade) can create convective air movements [85]. Kong et al. [35] analysed the effect of wind flow on a street canyon with trees, and Gromke and Ruck [86] probed the influence of two walls over a canyon vortex with perpendicular flow. This fact could help us to understand this environmental phenomenon. For this reason, the present study is suitable for modelling with a high degree of detail (aerobiological and meteorological data at an hourly scale) the environmental impact associated with one pollen type (Pinaceae) and its relationship with green infrastructure and the impact on buildings to establish and represent future models for urban planning.

Kubota et al. [87] studied the impacts of land use changes to propose green strategies. These authors analysed the effect of air temperature and wind speed and direction at several heights at 3-hour intervals in several conditions: built-up area, irrigated cropland and pasture, mixed cropland, mixed shrublands and mixed forest. The daytime peak air temperature in the master plan conditions was projected to maintain almost the same level as the current condition. However, high temperature areas would be broadly more abundant in the planned built-up areas. Yeo and Yee [17], in the development of an automated modeller of environment geographic information systems (E-GIS) for eco-friendly city planning, considered aspects such as planned city GIS, 2D GIS layers, the formation of 3D building volume and the formation of 3D urban GIS and aerial imaging to create a conceptual model. All these bearings were applied in our study to complement the shortage of effective methods for evaluating the distribution of buildings to plan and manage their arrangement in green spaces. Tong [18] proposed an index of distribution (IOD) based on a genetic algorithm to describe the distribution pattern of buildings in green spaces [18] such as public parks, and they argued that the scale of single buildings or the distribution of the building group will affect the local ecological environment and landscape significantly. Our study analysed the composition of elements of a green infrastructure and environmental conditions in more detail.

From all project management domains associated with BIM in a study by Ding et al. [8], safety, quality and schedule management are most related to those of the present study. This study adopted a 3D model to ascertain the coupled effects of building-tree arrangements on outdoor Pinaceae pollen. Another atmospheric parameter $\left(\mathrm{PM}_{2.5}\right)$ was evaluated in terms of height influence [37]. The results represent an advance for improving public health awareness and have benefits for urban planners in architectural and tree planting design to create a comfortable and healthy environment.

BIM technology allows 4D analysis [14]. Fig. 10 shows a wind direction of $123^{\circ}$, from the largest mass of pine trees to the samplers, with a velocity of $0.36 \mathrm{~m} / \mathrm{s}$. This result corresponds to the highest pollen concentration of this hourly episode. In addition, the highest hourly concentration of pollen occurred in the terrace sampler (3866 grains/ $\mathrm{m}^{3}$ ), in contrast with a concentration of 1091 grains $/ \mathrm{m}^{3}$ in the garden. This result shows that the pines trees in the area surrounding the building also affected the terrace sampler and that wind speed is not sufficient for the pollen to reach the garden sampler. This finding is consistent with the results of Sharma and Khanduri [52], who showed that the distance reached by the Pinus pollen shows logarithmic decay; the pines closest to the building are in the most effective range. However, the study by Sharma and Khanduri [52] did not mention the influence of wind speed, which shows a statistically significant correlation with Pinus pollen concentration [50]. One hour later (Fig. 10b), the wind direction remained similar $\left(106^{\circ}\right)$, but the speed wind had almost doubled $(0.61 \mathrm{~m} / \mathrm{s})$. We observed that the difference between the pollen concentration of the terrace sampler and the garden sampler was small. Indeed, higher wind speeds resulted in pine pollen from the closest environment reaching the garden sampler. Finally, $1 \mathrm{~h}$ later (Fig. 10c), the wind direction changed $\left(214^{\circ}\right)$, and the speed doubled $(1.19 \mathrm{~m} / \mathrm{s})$, which caused the pollen input to arise mainly from the pines in the garden. In this situation, the highest concentration of pollen occurred in the garden sampler, 3035 grains $/ \mathrm{m}^{3}$ compared to 1868 grains $/ \mathrm{m}^{3}$ on the terrace. This result shows the influence of the distance of the sampler on the concentration since the greater mass of pines on which the wind indexes was within the $50 \mathrm{~m}$ radius of action of the garden sampler and somewhat further away from the terrace sampler.

Our results showed that local air quality is strongly dependent on the relationship between meteorological conditions, the presence of vegetated green space and the $3 \mathrm{D}$ configuration of the building. The effect of the urban canopy (buildings and trees) on air pollutant dispersion has been shown to be complex and highly spatially dependent. Therefore, the knowledge produced in the application of BIM in urban planning has the goal of optimizing the role of green areas on human comfort and health [88]. The presented integration provides significant opportunities to reduce environmental impacts [1], allowing special attention to be paid to the evaluation of green infrastructures, such as tree plantings [27], and it can provide another set of goals for urban planners and engineers in urban systems for urban (re)-development [20]. Moreover, our findings could help in understanding other parameters in the resilient city concept. For this, it is necessary to consider whether planning for adaptation includes measures that address all types of risk factors and, at the same time, related environmentally, what make cities hotspots of risk [16]. This study represents a first attempt at considering the study area. Although a wider area would provide a more precise modelling, more aerodynamic wind effects would need to be measured, which would increase the difficulties in the interpretation of results.

The novel results of this study could be framed within the new rules of the green cities related to urban sustainability management [19]. Together with several previous comparisons, our study contributes to the development of ecology tools for design and construction, the development of dynamic physical models, and the incorporation of topological interlocking and optimization methods to building construction [89]. A new proposal related to our study is to produce a mash-up visualization of the social sensing environment [74] and to apply the data in real-time progress management [90].

\section{Conclusions}

Pines trees in BIM models of green areas and modelling of buildings in their environment were studied. Hourly pollen Pinaceae peaks did not follow constant hourly patterns in time for the same sampler; however, the average data showed a correlation between spore traps at 
different heights and distances. The daily pattern of temperatures affected hourly peaks, but wind speed modified this regular pattern and may even have been responsible for the appearance of two peaks in some cases. Airborne pollen concentration may be higher at higher elevations, depending on building design, the hour of the day and the wind. The results of this study help to define environmental variables (airborne pollen) that should be considered in construction of buildings and how proceed to integrate its modelling in urban planning. Our results showed that local air quality is strongly dependent on the relationship between meteorological conditions, the presence of vegetated green space and the 3D configuration of the building. The effect of the urban canopy (buildings and trees) on air pollutant dispersion has been shown to be complex and highly spatially dependent. So, it will allow technicians to add environmental health criteria in the design of building envelope voids (size, placement and orientation). From all project management domains associated with BIM, safety, quality and schedule management are most related to those of the present study. BIM technology allows 4D analysis in this new line research. Consequently, the novel use of BIM in aerobiology can be a useful tool towards the construction of "pollen free" buildings, considering the nearness of ornamental trees, potential risk of pollen grains, pollen grain dispersion and meteorology for urban planning.

\section{Acknowledgements}

This work was made possible by funds from research project PRI IB16029 and research group aid GR15060 financed by the regional government, Junta de Extremadura (Spain) and the European Regional Development Fund.

\section{References}

[1] P. Saieg, E.D. Sotelino, D. Nascimento, R.G.G. Caiado, Interactions of building information modeling, lean and sustainability on the architectural, engineering and construction industry: a systematic review, J. Clean. Prod. 174 (Supplement C) (2018) 788-806 0959-6526 https://doi.org/10.1016/j.jclepro.2017.11.030 http:// www.sciencedirect.com/science/article/pii/S0959652617326811.

[2] R.G.G. Caiado, R. de Freitas Dias, L.V. Mattos, O.L.G. Quelhas, W. Leal Filho, Towards sustainable development through the perspective of eco-efficiency - a systematic literature review, J. Clean. Prod. 165 (Supplement C) (2017) 890-904 0959-6526 https://doi.org/10.1016/j.jclepro.2017.07.166 http://www. sciencedirect.com/science/article/pii/S0959652617316128.

[3] M.S. Oh, S. Na, Building information modelling (BIM) based $\mathrm{CO}_{2}$ emissions assessment in the early design stage, Int. J. Civ. Eng. Technol. 8 (5) (2017) 1411-1425 https://www.scopus.com/inward/record.uri? eid =2-s2.0-85021652899\& partnerID $=40 \& m d 5=a c 368 b 60 \mathrm{c} 12041 \mathrm{a} 80 \mathrm{a} 9155 \mathrm{ad} 4 \mathrm{f} 82 \mathrm{~d} 9 \mathrm{~b} 7$.

[4] L. Chen, W. Pan, BIM-aided variable fuzzy multi-criteria decision making of lowcarbon building measures selection, Sustain. Cities Soc. 27 (Supplement C) (2016) 222-232 2210-6707 https://doi.org/10.1016/j.scs.2016.04.008 http://www. sciencedirect.com/science/article/pii/S2210670716300610.

[5] T. El-Diraby, T. Krijnen, M. Papagelis, BIM-based collaborative design and sociotechnical analytics of green buildings, Autom. Constr. 82 (2017) 59-74, https://doi. org/10.1016/j.autcon.2017.06.004 https://www.scopus.com/inward/record.uri? eid $=2$-s2.0-85021368875\&doi $=10.1016 \% 2 \mathrm{fj}$. autcon. $2017.06 .004 \&$ partnerID $=40$ \&md5 $=\mathrm{a} 4748 \mathrm{dc0}$ ac73da40f5241b3c3e8ea724.

[6] M. Marzouk, M. El-Zayat, A. Aboushady, Assessing environmental impact indicators in road construction projects in developing countries, Sustain. (Switz.) 9 (5) (2017), https://doi.org/10.3390/su9050843 https://www.scopus.com/inward/record.uri? eid $=2$-s2.0-85019835810\&doi $=10.3390 \% 2$ fsu9050843\&partnerID $=40 \& \mathrm{md} 5=$ 662bd1c20e733cb4eefb5ff0ee091d1a.

[7] S. Lee, S. Tae, S. Roh, T. Kim, Green template for life cycle assessment of buildings based on building information modeling: focus on embodied environmental impact, Sustain. (Switz.) 7 (12) (2015) 16498-16512, https://doi.org/10.3390/ su71215830 https://www.scopus.com/inward/record.uri?eid =2-s2.084952333230\&doi $=10.3390 \% 2$ fsu71215830\&partnerID $=40 \&$ md5 $=$ 944f378587bd7035721857d2633bdb81.

[8] L. Ding, Y. Zhou, B. Akinci, Building Information Modeling (BIM) application framework: the process of expanding from 3D to computable nD, Autom. Constr. 46 (Supplement C) (2014) 82-93 0926-5805 https://doi.org/10.1016/j.autcon.2014. 04.009 http://www.sciencedirect.com/science/article/pii/S092658051400096X.

[9] X. Wei, W. Bonenberg, M. Zhou, J. Wang, X. Wang, The case study of BIM in urban planning and design, Adv. Intell. Syst. Comput. 600 (2018) 207-217, https://doi. org /10.1007/978-3-319-60450-3 20.

[10] C. Eastman, P. Teicholz, R. Sacks, K. Liston, BIM Handbook: A Guide to Building Information Modeling for Owners, Managers, Designers, Engineers and Contractors, 2nd edition, John Wiley \& Sons, 978-0-470-54137-1, 2011https://www.wiley.com/
WileyCDA/WileyTitle/productCd-0470541377,miniSiteCd-BSG.html.

[11] S. Sharma, A. Sawhney, M. Arif, Parametric modelling for designing offsite construction, Procedia Eng. 196 (June) (2017) 1114-1121, https://doi.org/10.1016/j. proeng.2017.08.069 https://www.sciencedirect.com/science/article/pii/ S187770581733196X.

[12] B. Atazadeh, M. Kalantari, A. Rajabifard, S. Ho, Modelling building ownership boundaries within BIM environment: a case study in Victoria, Australia, Comput. Environ. Urban. Syst. 61 (2017) 24-38, https://doi.org/10.1016/j.compenvurbsys. 2016.09.001 https://www.sciencedirect.com/science/article/pii/ S0198971516302290.

[13] M. Mawlana, F. Vahdatikhaki, A. Doriani, A. Hammad, Integrating 4D modeling and discrete event simulation for phasing evaluation of elevated urban highway reconstruction projects, Autom. Constr. 60 (Supplement C) (2015) 25-38 09265805 https://doi.org/10.1016/j.autcon.2015.09.005 http://www.sciencedirect. com/science/article/pii/S0926580515001983.

[14] M.S. Altaf, Z. Hashisho, M. Al-Hussein, A method for integrating occupational indoor air quality with building information modeling for scheduling construction activities, Can. J. Civ. Eng. 41 (3) (2014) 245-251, https://doi.org/10.1139/cjce2013-0230 https://www.scopus.com/inward/record.uri?eid =2-s2.0-84896828105 $\&$ doi $=10.1139 \% 2$ fcjce-2013-0230\&partnerID $=40 \& \mathrm{md} 5=$ e7bd7b2ac912846ee4151354e090a891.

[15] G.D.P.A. Aschwanden, S. Haegler, F. Bosché, L. Van Gool, G. Schmitt, Empiric design evaluation in urban planning, Autom. Constr. 20 (3) (2011) 299-310 0926 5805 https://doi.org/10.1016/j.autcon.2010.10.007 http://www.sciencedirect. com/science/article/pii/S0926580510001718.

[16] C. Wamsler, E. Brink, C. Rivera, Planning for climate change in urban areas: from theory to practice, J. Clean. Prod. 50 (Supplement C) (2013) 68-81 0959-6526 https://doi.org/10.1016/j.jclepro.2012.12.008 http://www.sciencedirect.com/ science/article/pii/S095965261200652X.

[17] I.-A. Yeo, J.-J. Yee, Development of an automated modeler of environment and energy geographic information (E-GIS) for ecofriendly city planning, Autom. Constr. 71 (Part 2) (2016) 398-413 0926-5805 https://doi.org/10.1016/j.autcon. 2016.08.009 http://www.sciencedirect.com/science/article/pii/ S0926580516301637.

[18] Z. Tong, A genetic algorithm approach to optimizing the distribution of buildings in urban green space, Autom. Constr. 72 (Part 1) (2016) 46-51 0926-5805 https://doi. org/10.1016/j.autcon.2016.10.001 http://www.sciencedirect.com/science/ article/pii/S0926580516302357.

[19] C.N. Madu, C.-h. Kuei, P. Lee, Urban sustainability management: a deep learning perspective, Sustain. Cities Soc. 30 (Supplement C) (2017) 1-17 2210-6707 https:// doi.org/10.1016/j.scs.2016.12.012 http://www.sciencedirect.com/science/ article/pii/S2210670716304590.

[20] A. Pandit, E.A. Minné, F. Li, H. Brown, H. Jeong, J.-A.C. James, J.P. Newell, M. Weissburg, M.E. Chang, M. Xu, P. Yang, R. Wang, V.M. Thomas, X. Yu, Z. Lu, J.C. Crittenden, Infrastructure ecology: an evolving paradigm for sustainable urban development, J. Clean. Prod. 163 (Supplement) (2017) S19-S27 0959-6526 https:// doi.org/10.1016/j.jclepro.2015.09.010 http://www.sciencedirect.com/science/ article/pii/S0959652615012317.

[21] D. Astiaso Garcia, Green areas management and bioengineering techniques for improving urban ecological sustainability, Sustain. Cities Soc. 30 (Supplement C) (2017) 108-117 2210-6707 https://doi.org/10.1016/j.scs.2017.01.008 http:// www.sciencedirect.com/science/article/pii/S2210670716305224.

[22] R. Wang, J. Zhao, Demographic groups' differences in visual preference for vegetated landscapes in urban green space, Sustain. Cities Soc. 28 (Supplement C) (2017) 350-357 2210-6707 https://doi.org/10.1016/j.scs.2016.10.010 http:// www.sciencedirect.com/science/article/pii/S2210670716304024.

[23] R. Wang, J. Zhao, Z. Liu, Consensus in visual preferences: the effects of aesthetic quality and landscape types, Urban For. Urban Green. 20 (Supplement C) (2016) 210-217 1618-8667 https://doi.org/10.1016/j.ufug.2016.09.005 http://www. sciencedirect.com/science/article/pii/S1618866715300091.

[24] G. Hatvani-Kovacs, M. Belusko, N. Skinner, J. Pockett, J. Boland, Heat stress risk and resilience in the urban environment, Sustain. Cities Soc. 26 (Supplement C) (2016) 278-288 2210-6707 https://doi.org/10.1016/j.scs.2016.06.019 http:// www.sciencedirect.com/science/article/pii/S2210670716301299.

[25] C. Cortinovis, D. Geneletti, Ecosystem services in urban plans: what is there, and what is still needed for better decisions, Land Use Policy 70 (Supplement C) (2018) 298-312 0264-8377 https://doi.org/10.1016/j.landusepol.2017.10.017 http:// www.sciencedirect.com/science/article/pii/S0264837717302661.

[26] H. Liu, Y. Hu, F. Li, L. Yuan, Associations of multiple ecosystem services and disservices of urban park ecological infrastructure and the linkages with socioeconomic factors, J. Clean. Prod. 174 (Supplement C) (2018) 868-879 0959-6526 https://doi.org/10.1016/j.jclepro.2017.10.139 http://www.sciencedirect.com/ science/article/pii/S0959652617324459.

[27] E.P. Law, S.A.W. Diemont, T.R. Toland, A sustainability comparison of green infrastructure interventions using emergy evaluation, J. Clean. Prod. 145 (Supplement C) (2017) 374-385 0959-6526 https://doi.org/10.1016/j.jclepro. 2016.12.039 http://www.sciencedirect.com/science/article/pii/ S0959652616320947.

[28] T.E. Morakinyo, A. Lai, K.K.-L. Lau, E. Ng, Thermal benefits of vertical greening in a high-density city: case study of Hong Kong, Urban For. Urban Green. (2017), https://doi.org/10.1016/j.ufug.2017.11.010 1618-8667 http://www.sciencedirect. com/science/article/pii/S1618866717305551.

[29] G. Kim, An integrated system of urban green infrastructure on different types of vacant land to provide multiple benefits for local communities, Sustain. Cities Soc. 36 (Supplement C) (2018) 116-130 2210-6707 https://doi.org/10.1016/j.scs.2017. 10.022 http://www.sciencedirect.com/science/article/pii/S2210670716303766. 
[30] J. Breuste, M. Artmann, J. Li, M. Xie, Special issue on green infrastructure for urban sustainability, J. Urban Plann. Dev. 141 (3) (2015) A20150010733-9488 https:// doi.org/10.1061/(ASCE)UP.1943-5444.0000291.

[31] N. Kabisch, S. Qureshi, D. Haase, Human-environment interactions in urban green spaces - a systematic review of contemporary issues and prospects for future research, Environ. Impact Assess. Rev. 50 (2015) 25-34 0195-9255 https://doi.org/ 10.1016/j.eiar.2014.08.007 http://www.sciencedirect.com/science/article/pii/ S0195925514000754.

[32] R. Scolozzi, D. Geneletti, A multi-scale qualitative approach to assess the impact of urbanization on natural habitats and their connectivity, Environ. Impact Assess. Rev. 36 (2012) 9-22 0195-9255 https://doi.org/10.1016/j.eiar.2012.03.001 http://www.sciencedirect.com/science/article/pii/S0195925512000194.

[33] C. Ortolani, M. Vitale, The importance of local scale for assessing, monitoring and predicting of air quality in urban areas, Sustain. Cities Soc. 26 (Supplement C) (2016) 150-160 2210-6707 https://doi.org/10.1016/j.scs.2016.06.001 http:// www.sciencedirect.com/science/article/pii/S221067071630107X.

[34] A. Gülten, U.T. Aksoy, H.F. Öztop, Influence of trees on heat island potential in an urban canyon, Sustain. Cities Soc. 26 (Supplement C) (2016) 407-418 2210-6707 https://doi.org/10.1016/j.scs.2016.04.006 http://www.sciencedirect.com/ science/article/pii/S2210670716300592.

[35] L. Kong, K.K.-L. Lau, C. Yuan, Y. Chen, Y. Xu, C. Ren, E. Ng, Regulation of outdoor thermal comfort by trees in Hong Kong, Sustain. Cities Soc. 31 (Supplement C) (2017) 12-25 2210-6707 https://doi.org/10.1016/j.scs.2017.01.018 http://www. sciencedirect.com/science/article/pii/S2210670716306576.

[36] S. Jin, J. Guo, S. Wheeler, L. Kan, S. Che, Evaluation of impacts of trees on PM2.5 dispersion in urban streets, Atmos. Environ. 99 (Supplement C) (2014) 277-287 1352-2310 https://doi.org/10.1016/j.atmosenv.2014.10.002 http://www. sciencedirect.com/science/article/pii/S1352231014007791.

[37] B. Hong, B. Lin, H. Qin, Numerical investigation on the coupled effects of buildingtree arrangements on fine particulate matter (PM2.5) dispersion in housing blocks, Sustain. Cities Soc. 34 (Supplement C) (2017) 358-370 2210-6707 https://doi.org/ 10.1016/j.scs.2017.07.005 http://www.sciencedirect.com/science/article/pii/ S221067071630765X.

[38] V.L. Castaldo, A.L. Pisello, I. Pigliautile, C. Piselli, F. Cotana, Microclimate and air quality investigation in historic hilly urban areas: experimental and numerical investigation in central Italy, Sustain. Cities Soc. 33 (Supplement C) (2017) 27-44 2210-6707 https://doi.org/10.1016/j.scs.2017.05.017 http://www.sciencedirect. com/science/article/pii/S2210670716304322.

[39] I. Silva-Palacios, S. Fernández-Rodríguez, P. Durán-Barroso, R. Tormo-Molina, J.M. Maya-Manzano, Á. Gonzalo-Garijo, Temporal modelling and forecasting of the airborne pollen of Cupressaceae on the southwestern Iberian Peninsula, Int. J. Biometeorol. 60 (2) (2016) 297-306, https://doi.org/10.1007/s00484-015-1026-6 http://www.scopus.com/inward/record.url?eid = 2-s2.0-84931864406\& partnerID $=40 \& \mathrm{md} 5=459 \mathrm{a} 78219 \mathrm{~b} 879 \mathrm{bfbb0660b4970970490.}$

[40] S. Fernández-Rodríguez, P. Durán-Barroso, I. Silva-Palacios, R. Tormo-Molina, J.M. Maya-Manzano, Á. Gonzalo-Garijo, Regional forecast model for the Olea pollen season in Extremadura (SW Spain), Int. J. Biometeorol. 60 (10) (2016) 1509-1517, https://doi.org/10.1007/s00484-016-1141-z https://link.springer.com/article/10. 1007/s00484-016-1141-z?wt_mc = internal.event.1.SEM.ArticleAuthorOnlineFirst.

[41] S. Fernández-Rodríguez, P. Durán-Barroso, I. Silva-Palacios, R. Tormo-Molina, J.M. Maya-Manzano, Á. Gonzalo-Garijo, Quercus long-term pollen season trends in the southwest of the Iberian Peninsula, Process Saf. Environ. Prot. 101 (2016) 152-159, https://doi.org/10.1016/j.psep.2015.11.008 https://www.scopus.com/ inward/record.uri? eid =2-s2.0-84984922313\&doi $=10.1016 \% 2 \mathrm{fj} . p s e p .2015 .11$. 008\&partnerID $=40 \&$ md5 $=$ fe4de1de4440c66548441e6c7815b071.

[42] S. Fernández-Rodríguez, P. Durán-Barroso, I. Silva-Palacios, R. Tormo-Molina, J.M. Maya-Manzano, Á. Gonzalo-Garijo, Forecast model of allergenic hazard using trends of Poaceae airborne pollen over an urban area in SW Iberian Peninsula (Europe), Nat. Hazards 84 (1) (2016) 121-137, https://doi.org/10.1007/s11069016-2411-0 https://www.scopus.com/inward/record.uri?eid =2-s2.084987677837\&partnerID = 40\&md5 = 8ba388264c4b7db2aa0031830cd75e02.

[43] S. Fernández-Rodriguez, P. Durán-Barroso, I. Silva-Palacios, R. Tormo-Molina, J.M. Maya-Manzano, Á. Gonzalo-Garijo, A. Monroy-Colin, Environmental assessment of allergenic risk provoked by airborne grass pollen through forecast model in a Mediterranean region, J. Clean. Prod. (2018), https://doi.org/10.1016/j.jclepro. 2017.11.226 in press https://www.sciencedirect.com/science/article/pii/ S0959652617328998.

[44] D. García De León, H. García-Mozo, C. Galán, P. Alcázar, M. Lima, J.L. GonzálezAndújar, Disentangling the effects of feedback structure and climate on Poaceae annual airborne pollen fluctuations and the possible consequences of climate change, Sci. Total Environ. 530-531 (2015) 103-109, https://doi.org/10.1016/j. scitotenv.2015.05.104 http://www.scopus.com/inward/record.url?eid=2-s2.0 84930615224\&partnerID = 40\&md5 =9e039c8d2de7891b23001922f7e9d552

[45] M.J. Simard, D.L. Benoit, Effect of repetitive mowing on common ragweed (Ambrosia artemisiifolia L.) pollen and seed production, Ann. Agric. Environ. Med. 18 (1) (2011) 55-62 https://www.scopus.com/inward/record.uri? eid = 2-s2.0 79960375245\&partnerID $=40 \& \mathrm{md} 5=0137 \mathrm{cdac} 649 \mathrm{f} 6949 \mathrm{~d} 4 \mathrm{e} 315 \mathrm{~b} 0 \mathrm{f} 9260200$.

[46] H. Ribeiro, F. Guimarães, L. Duque, F. Noronha, I. Abreu, Characterisation of particulate matter on airborne pollen grains, Environ. Pollut. 206 (2015) 7-16, https:// doi.org/10.1016/j.envpol.2015.06.015 https://www.scopus.com/inward/record. uri? eid $=2$-s2.0-84934298718\&doi $=10.1016 \% 2 \mathrm{fj}$.envpol.2015.06.015\& partnerID $=40 \& \mathrm{md} 5=4978$ deac3a85e6e4387ffa8a95fcad58.

[47] J.M. Maya-Manzano, R. Tormo-Molina, S. Fernández-Rodríguez, I. Silva-Palacios, Á. Gonzalo-Garijo, Distribution of ornamental urban trees and their influence on airborne pollen, Landsc. Urban Plan. 157 (2017) 434-446, https://doi.org/10. 1016/j.landurbplan.2016.08.011 https://www.sciencedirect.com/science/article/
pii/S0169204616301645.

[48] E.D. 2011/92/EU, European Directive on assessment of the effects of certain public and private projects on the environment, http://eur-lex.europa.eu/legal-content/ EN/TXT/?uri = celex\%3A32011L0092, (2011).

[49] E.A. 21/2013, Spanish law on environmental assessment, https://www.boe.es/ buscar/pdf/2013/BOE-A-2013-12913-consolidado.pdf, (2013).

[50] S. Fernández-Rodríguez, R. Tormo-Molina, J.M. Maya-Manzano, I. Silva-Palacios, Á. Gonzalo-Garijo, A comparative study on the effects of altitude on daily and hourly airborne pollen counts, Aerobiologia 30 (3) (2014) 257-268 http://www. scopus.com/inward/record.url?eid $=2$-s2.0-84906221244\&partnerID $=40 \& \mathrm{md} 5=$ 19aaebf671a7604357d02d3368252179.

[51] D.T. Pocknall, Modern pollen spectra from mountain localities, South Island, New Zealand, N. Z. J. Bot. 20 (4) (1982) 361-371, https://doi.org/10.1080/0028825X 1982.10428505 https://www.scopus.com/inward/record.uri?eid =2-s2.00020428501 \&doi $=10.1080 \% 2$ f0028825X.1982.10428505\&partnerID $=40$ \& md5 $=$ f21f44cdded1019a6fd196fac1373de2.

[52] C.M. Sharma, V.P. Khanduri, Pollen-mediated gene flow in Himalayan long needle pine (Pinus roxburghii Sargent), Aerobiologia 23 (2) (2007) 153-158, https://doi. org/10.1007/s10453-007-9056-0 https://www.scopus.com/inward/record.uri? eid $=2$-s2.0-34548124738\& doi $=10.1007 \% 2$ fs10453-007-9056-0\&partnerID $=40 \&$ md5 $=3 c 47 d c 1 a 549 d 52 c 8 c 7 a 10 c c c 5383 e 79 e$.

[53] C. Galán, J. Emberlin, E. Domínguez, R.H. Bryant, F. Villamandos, A comparative analysis of daily variations in the Gramineae pollen counts at Córdoba, Spain and London, UK, Grana 34 (3) (1995) 189-198 0017-3134 https://doi.org/10.1080/ 00173139509429042.

[54] F.J. Toro, M. Recio, M.d.M. Trigo, B. Cabezudo, Predictive models in aerobiology: data transformation, Aerobiologia 14 (2) (1998) 179 1573-3025 https://doi.org/ 10.1007/bf02694203 https://doi.org/10.1007/BF02694203.

[55] A. Stach, M. Smith, J.C. Prieto Baena, J. Emberlin, Long-term and short-term forecast models for Poaceae (grass) pollen in Poznań, Poland, constructed using regression analysis, Environ. Exp. Bot. 62 (3) (2008) 323-332 0098-8472 https:// doi.org/10.1016/j.envexpbot.2007.10.005 http://www.sciencedirect.com/ science/article/pii/S0098847207001748.

[56] Y.-T. Tseng, S. Kawashima, S. Kobayashi, S. Takeuchi, K. Nakamura, Algorithm for forecasting the total amount of airborne birch pollen from meteorological conditions of previous years, Agric. For. Meteorol. 249 (2018) 35-43 0168-1923 https:// doi.org/10.1016/j.agrformet.2017.11.021 http://www.sciencedirect.com/science/ article/pii/S0168192317303945.

[57] L.A. Darrow, J. Hess, C.A. Rogers, P.E. Tolbert, M. Klein, S.E. Sarnat, Ambient pollen concentrations and emergency department visits for asthma and wheeze, J. Allergy Clin. Immunol. 130 (3) (2012), https://doi.org/10.1016/j.jaci.2012.06.020 630-638.e634 https://www.scopus.com/inward/record.uri?eid =2-s2.0$84865684366 \&$ doi $=10.1016 \% 2 \mathrm{fj}$. jaci. $2012.06 .020 \&$ partnerID $=40 \& \mathrm{md} 5=$ 0809ce888219b7436c4cdfbb595d3a38.

[58] R.E. Dales, S. Cakmak, S. Judek, F. Coates, Tree pollen and hospitalization for asthma in urban Canada, Int. Arch. Allergy Immunol. 146 (3) (2008) 241-247, https://doi.org/10.1159/000116360 https://www.scopus.com/inward/record.uri? eid $=2$-s2.0-45149092910\&doi $=10.1159 \% 2$ f000116360\&partnerID $=40 \& \mathrm{md} 5=$ 50a053e65d80ce73f7c0986255ab730e.

[59] L.A. Schwietz, D.W. Goetz, B.A. Whisman, M.J. Reid, Cross-reactivity among conifer pollens, Ann Allergy Asthma Immunol 84 (1) (2000) 87-93, https://doi.org/10. 1016/S1081-1206(10)62746-9 https://www.scopus.com/inward/record.uri?eid= 2-s2.0-0033953289\&doi $=10.1016 \% 2 f S 1081-1206 \% 2810 \% 2962746-9 \&$ partnerID $=40 \&$ md5 $=$ a2556de8d559311d7dc26fbfd039f61f.

[60] J. Domínguez-Ortega, M.Á. López-Matas, M.D. Alonso, A. Feliú, J. Ruiz-Hornillos, E. González, R. Moya, J. Carnés, Prevalence of allergic sensitization to conifer pollen in a high cypress exposure area, Allergy Rhinol. 7 (4) (2016) e200-e206 2152-6575 2152-6567 https://doi.org/10.2500/ar.2016.7.0183 http://www.ncbi. nlm.nih.gov/pmc/articles/PMC5244279/.

[61] J.M. Hirst, An automatic volumetric spore trap, Ann. Appl. Biol. 39 (2) (1952) 257-265 https://onlinelibrary.wiley.com/doi/abs/10.1111/j.1744-7348.1952. tb00904.x.

[62] R. Tormo-Molina, J.M. Maya-Manzano, S. Fernández-Rodríguez, Á. Gonzalo-Garijo, I. Silva-Palacios, Influence of environmental factors on measurements with Hirst spore traps, Grana 52 (1) (2013) 59-70, https://doi.org/10.1080/00173134.2012 718359 http://www.scopus.com/inward/record.url? eid =2-s2.0-84875964644\& partnerID $=40 \&$ md5 $=7 \mathrm{dd} 32 \mathrm{~b} 8316720 \mathrm{a} 1 \mathrm{a} 7 \mathrm{bd} 967 \mathrm{cf} 4 \mathrm{a} 00 \mathrm{a} 54 \mathrm{~d}$.

[63] J.M. Maya-Manzano, S. Fernández-Rodríguez, I. Silva-Palacios, Á. Gonzalo-Garijo, R. Tormo-Molina, Comparison between two adhesives (silicone and petroleum jelly) in Hirst pollen traps in a controlled environment, Grana 57 (1-2) (2018) 137-143, https://doi.org/10.1080/00173134.2017.1319973 https://www.scopus.com/ inward/record.uri? eid $=2$-s2.0-85019730185\&doi $=10.1080 \% 2$ f00173134.2017. 1319973\&partnerID $=40 \&$ md5 $=$ abb09cd0a1842bccd7172546ba4445b8.

[64] C. Galán, P. Cariñanos, P. Alcázar, E. Dominguez-Vilches, Spanish Aerobiology Network (REA) Management and Quality Manual, Servicio de Publicaciones Universidad de Córdoba, 978-84-690-6353-8, 2007.

[65] S. Nilsson, S. Persson, Tree pollen spectra in the Stockholm region (Sweden), 1973-1980, Grana 20 (3) (1981) 179-182 0017-3134 https://doi.org/10.1080/ 00173138109427661.

[66] K.M. Kensek, Integración de sensores medioambientales con $\{B I M\}$ : casos de estudio usando \{Arduino\}, \{Dynamo\}, y \{Revit\} \{API\}, Inf. Constr. 66 (2014) 536, https://doi.org/10.3989/ic.13.151 http://informesdelaconstruccion.revistas.csic. es/index.php/informesdelaconstruccion/article/view/3575/4027.

[67] C.f.A.a.t.B. Environment, Start With the Park, Cabe Space, 111 (2005) 1-84633000-9.

[68] C. Liu, T. Qi, X. Ma, The research on the impact assessment of visual landscape of 
country parks in Beijing, J. Environ. Eng. Landsc. Manag. 24 (1) (2016) 37-47, https://doi.org/10.3846/16486897.2015.1106545 https://www.scopus.com/ inward/record.uri?eid $=2$-s2.0-84962278560\&partnerID $=40 \& \mathrm{md} 5=$ $5889079 d 22$ facf197af437c8f06f8548.

[69] B. Quintana, S.A. Prieto, A. Adán, F. Bosché, Door detection in 3D coloured point clouds of indoor environments, Autom. Constr. 85 (2018) 146-166, https://doi. org/10.1016/j.autcon.2017.10.016 https://www.sciencedirect.com/science/ article/pii/S0926580516302400.

[70] L. Leung, I. Farmakin, T. Kwok, Relationships between indoor facilities management components and elderly people's quality of life: a study of private domestic buildings, Habitat Int. 66 (2017) 13-23, https://doi.org/10.1016/j.habitatint.2017. 05.002 https://www.sciencedirect.com/science/article/pii/S0197397516306622.

[71] R. Tormo, A. Muñoz, I. Silva, F. Gallardo, Pollen production in anemophilous trees, Grana 35 (1) (1996) 38-46 http://www.scopus.com/inward/record.url?eid=2-s2.

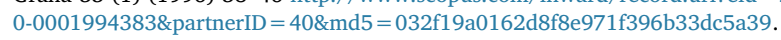

[72] J.M. Maya Manzano, M. Sadyś, R. Tormo Molina, S. Fernández Rodríguez, J. Oteros, I. Silva Palacios, Á. Gonzalo Garijo, Relationships between airborne pollen grains, wind direction and land cover using GIS and circular statistics, Sci. Total Environ. 584 (2017) 603-613, https://doi.org/10.1016/j.scitotenv.2017.01.085 https:// www.sciencedirect.com/science/article/pii/S0048969717300955.

[73] A. Damialis, E. Kaimakamis, M. Konoglou, I. Akritidis, C. Traidl-Hoffmann, D. Gioulekas, Estimating the abundance of airborne pollen and fungal spores at variable elevations using an aircraft: how high can they fly? Sci. Rep. 7 (1-11) (2017) 2045-2322, https://doi.org/10.1038/srep44535 http://www.ncbi.nlm.nih. gov/pmc/articles/PMC5353600/.

[74] S.A. Kim, D. Shin, Y. Choe, T. Seibert, S.P. Walz, Integrated energy monitoring and visualization system for Smart Green City development: designing a spatial information integrated energy monitoring model in the context of massive data management on a web based platform, Autom. Constr. 22 (Supplement C) (2012) 51-59 0926-5805 https://doi.org/10.1016/j.autcon.2011.07.004 http://www. sciencedirect.com/science/article/pii/S0926580511001440.

[75] J. Balado, L. Díaz-Vilariño, P. Arias, M. Soilán, Automatic building accessibility diagnosis from point clouds, Autom. Constr. 82 (Supplement C) (2017) 103-111 0926-5805 https://doi.org/10.1016/j.autcon.2017.06.026 http://www. sciencedirect.com/science/article/pii/S0926580517302029.

[76] B. Akinci, M. Fischer, R. Levitt, R. Carlson, Formalization and automation of time-space conflict analysis, J. Comput. Civ. Eng. 16 (2) (2002) 124-135 08873801 https://ascelibrary.org/doi/10.1061/\%28ASCE\%290887-3801\%282002\% 2916\%3A2\%28124\%29.

[77] Y. Lu, Z. Wu, R. Chang, Y. Li, Building Information Modeling (BIM) for green buildings: a critical review and future directions, Autom. Constr. 83 (2017) 134-148, https://doi.org/10.1016/j.autcon.2017.08.024 https://www. sciencedirect.com/science/article/pii/S092658051730095X.

[78] A. Sharifi, From Garden City to Eco-urbanism: the quest for sustainable neighbor hood development, Sustain. Cities Soc. 20 (Supplement C) (2016) 1-16 2210-6707 https://doi.org/10.1016/j.scs.2015.09.002 http://www.sciencedirect.com/ science/article/pii/S2210670715300287.

[79] D. La Rosa, C. Takatori, H. Shimizu, R. Privitera, A planning framework to evaluate demands and preferences by different social groups for accessibility to urban greenspaces, Sustain. Cities Soc. 36 (Supplement C) (2018) 346-362 2210-6707 https://doi.org/10.1016/j.scs.2017.10.026 http://www.sciencedirect.com/ science/article/pii/S2210670717311605.

[80] C.-M. Hsieh, J.-J. Li, L. Zhang, B. Schwegler, Effects of tree shading and transpiration on building cooling energy use, Energ. Buildings 159 (Supplement C) (2018) 382-397 0378-7788 https://doi.org/10.1016/j.enbuild.2017.10.045 http://www.sciencedirect.com/science/article/pii/S0378778817313294.

[81] M.J. Velasco-Jiménez, P. Alcázar, A. Valle, M.M. Trigo, F. Minero, E. DomínguezVilches, C. Galán, Aerobiological and ecological study of the potentially allergenic ornamental plants in south Spain, Aerobiologia 30 (1) (2014) 91-101, https://doi. org/10.1007/s10453-013-9311-5 http://www.scopus.com/inward/record.url? eid $=2$-s2.0-84903372318\&partnerID $=40 \& \mathrm{md} 5=$ 3cf149bc98e70f51ae5491da6bbd85b4.

[82] H. Ribeiro, I. Abreu, A 10-year survey of allergenic airborne pollen in the city of Porto (Portugal), Aerobiologia 30 (3) (2014) 333-344 http://www.scopus.com/ inward/record.url? eid $=2$-s2.0-84906239393\&partnerID $=40 \&$ md5 $=$ 030b967096f81150bb17018c7ed66241.

[83] U. Uguz, A. Guvensen, N.S. Tort, Annual and intradiurnal variation of dominant airborne pollen and the effects of meteorological factors in Çeşme (Izmir, Turkey), Environ. Monit. Assess. 189 (10) (2017), https://doi.org/10.1007/s10661-0176238-2 https://www.scopus.com/inward/record.uri? eid =2-s2.0-85030176604\& doi $=10.1007 \% 2$ fs $10661-017-6238-2 \&$ partnerID $=40 \& \mathrm{md} 5=$ bd22478a7e4c9633825194244d6022b2.

[84] A. Damialis, D. Gioulekas, C. Lazopoulou, C. Balafoutis, D. Vokou, Transport of airborne pollen into the city of Thessaloniki: the effects of wind direction, speed and persistence, Int. J. Biometeorol. 49 (3) (2005) 139-145, https://doi.org/10.1007/ s00484-004-0229-z https://www.scopus.com/inward/record.uri?eid=2-s2.0$12844268869 \&$ doi $=10.1007 \% 2 \mathrm{fs} 00484-004-0229$-z\&partnerID $=40 \& \mathrm{md} 5=$ e22513c1c35300970ac945412920095c.

[85] C. Peng, C. Li, Z. Zou, S. Shen, D. Sun, Improvement of air quality and thermal environment in an old city district by constructing wind passages, Sustainability 7 (2015) 12672-12692, https://doi.org/10.3390/su70912672 http://www.mdpi. com/2071-1050/7/9/12672.

[86] C. Gromke, B. Ruck, Influence of trees on the dispersion of pollutants in an urban street canyon-experimental investigation of the flow and concentration field, Atmos. Environ. 41 (16) (2007) 3287-3302 1352-2310 https://doi.org/10.1016/j. atmosenv.2006.12.043 http://www.sciencedirect.com/science/article/pii/ S1352231007000076.

[87] T. Kubota, H.S. Lee, A.R. Trihamdani, T.T.T. Phuong, T. Tanaka, K. Matsuo, Impacts of land use changes from the Hanoi Master Plan 2030 on urban heat islands: part 1. Cooling effects of proposed green strategies, Sustain. Cities Soc. 32 (Supplement C) (2017) 295-317 2210-6707 https://doi.org/10.1016/j.scs.2017.04.001 http:// www.sciencedirect.com/science/article/pii/S2210670716305716.

[88] J.H. Amorim, V. Rodrigues, R. Tavares, J. Valente, C. Borrego, CFD modelling of the aerodynamic effect of trees on urban air pollution dispersion, Sci. Total Environ. 461-462 (Supplement C) (2013) 541-551 0048-9697 https://doi.org/10.1016/j. scitotenv.2013.05.031 http://www.sciencedirect.com/science/article/pii/ S0048969713005743.

[89] T.-W. Chang, T.J. Moleta, D. Park, COMPUTATIONAL DESIGN in the past, present and future of digital architecture, Autom. Constr. 72 (Part 1) (2016) 1-2 0926-5805 https://doi.org/10.1016/j.autcon.2016.10.006 http://www.sciencedirect.com/ science/article/pii/S092658051630303X.

[90] J. Matthews, P.E.D. Love, S. Heinemann, R. Chandler, C. Rumsey, O. Olatunj, Real time progress management: re-engineering processes for cloud-based BIM in construction, Autom. Constr. 58 (Supplement C) (2015) 38-47 0926-5805 https://doi. org/10.1016/j.autcon.2015.07.004 http://www.sciencedirect.com/science/ article/pii/S0926580515001478. 